\title{
Marriage: Cause or Mere Indicator of Future Earnings Growth?
}

\author{
Ronald Mincy \\ Jennifer Hill \\ Marilyn Sinkewicz.
}

\begin{abstract}
The hypothesis that marriage increases men's earnings has contributed to legislative support for the Healthy Marriage Initiative (HMI). However, previous studies of this phenomenon have not controlled for many relevant characteristics that select men into marriage, nor have they focused on low-income, unmarried fathers-the population targeted by HMI. We use the Fragile Families and Child Wellbeing Study, which measures many previously unobserved confounders, to test for a relationship between marriage and earnings. We use a variety of analytic strategies to control for selection (including differencing and propensity scores) and find no evidence of an effect of transitions to marriage on the earnings of unmarried fathers that differs from zero, either for the full sample or subsamples defined by race-ethnic category and baseline cohabitation status. (C) 2009 by the Association for Public Policy Analysis and Management.
\end{abstract}

It is a well-established empirical finding that married men have higher earnings than unmarried men. Does marriage itself cause this "marriage differential" or can the disparity be explained by the fact that, even before the event, men who marry differ from those who do not in ways that also lead them to earn more in the future?

The mechanism behind the observed association between marriage and men's earnings has been a central issue in family policy debates, most recently with regard to the Healthy Marriage Initiative (HMI). For instance, one of HMI's flagship demonstrations, Building Strong Families (BSF), targets couples who share a nonmarital birth and raise their (common) children together. Because of the instability of these arrangements and the risk for poorer child and family outcomes (so-called "fragile families"; see Carlson, McLanahan, \& England, 2004; Mincy, 1994; Mincy \& Pouncy, 1997), BSF provides support to help them strengthen their relationships and form and sustain healthy marriages (Amato, 2007; Dion et al., 2003). If marriage induces higher earnings for fathers in this population, and if BSF successfully promotes marriage, then this could lead to a reduction in child poverty (Thomas \& Sawhill, 2002).

Some argue, however, that relationship instability and other problems among poor and minority, unmarried parents are reasons to be skeptical that marriage will produce positive outcomes for these parents or their children (Furstenberg, 2007). For instance, there is considerable evidence that the shortage of men with stable jobs in low-income, minority populations reduces the marriage prospects for lowincome, single mothers (Fossett \& Kiecolt, 1993; Harknett \& McLanahan, 2004; Lichter, Leclere, \& McLaughlin, 1991; Lichter et al., 1992; South \& Lloyd, 1992; Wilson, 1987). Further, Edin and Kefalas (2005) propose that a low-income, single 
mother is looking for a father with sufficient earnings to help her acquire the amenities associated with middle class status, including a car and a home. In this case, differential selection into marriage may be at the root of the earnings differential between married and unmarried men, particularly with respect to disadvantaged men. Moreover, these mechanisms argue for providing different types of intervention. For example, several researchers have suggested that, in addition to relationship support services, HMI should attempt to increase the skills and earnings of unmarried fathers (Carlson, Garfinkel, et al., 2004; Carlson, McLanahan, \& England, 2004; Mincy \& Dupree, 2001).

In this paper we address this debate using new data and methods to attempt to identify the causal effect of transitions to marriage for a sample of relatively disadvantaged fathers. These men are initially unmarried, although either romantically involved or cohabiting with the mothers of their children. The remainder of the paper is organized as follows. We begin with a review of previous literature on the marriage differential, along with its limitations. We then highlight the contributions of our paper by describing our sample and methods. Next, we present the results of our analyses followed by a discussion of our findings and their policy implications.

\section{PREVIOUS LITERATURE}

\section{Hypotheses to Explain the Marriage Differential}

On average, married men have higher earnings than unmarried men (Antonovics \& Town, 2004; Stratton, 2002). It is possible that this differential is caused solely by the differential characteristics that select men into and out of marriage. However, several hypotheses also exist regarding how marriage might cause (at least part of) this differential. The most prominent explanation for the effect of marriage on men's earnings is that specialization in market production by men and household production by women leads married men to spend more time at work than unmarried men, resulting in higher wages (Becker, 1965, 1973, 1981; Mincer, 1962; Parsons, 1943, 1949). Moreover, the wages of men employed in high-status occupations (for example, politician and college professor) may reflect rewards for the uncompensated labor of their wives (Gallagher, 2003; Kanter, 1993; Papaneck, 1973).

Several alternative causal explanations for the marriage differential do not involve specialization. Employers may discriminate in favor of married workers because they know married men have families to support and consequently predict that they will work harder (Bartlett \& Callahan, 1984). Besides higher wages, married men may also have higher earnings than unmarried men because they work more hours. Kenny (1983) argues that they do so because of a greater perceived need for income. Nock (1998a) argues that they do so to conform to a social script requiring married men to protect and provide for wives and children, which is reflected in and enforced by law, custom, and religious practice. Finally, according to Nock (1998b), marriage provides men with social capital of the kind Coleman (1988) describes, including access to the family and friends of his wife who can help them locate jobs. In the social network literature, these contacts can also provide jobseekers with recommendations from sources employers trust, thereby improving their chances of being selected among many candidates for higher paying jobs (Aguilera, 2003, 2008; Neckerman \& Fernandez, 2003). By this logic, fathers who transition to marriage may have higher earnings than those who remain single, through the social capital that marriage provides.

The impact of marriage on earnings, should it exist, may vary by race-ethnicity or cohabitation status. Previous work suggests that marriage will have a smaller impact on the earnings of black than white husbands because, other things equal, black women work more hours and have higher labor force participation rates than white women, which makes specialization in market work more difficult for these 
men (Rodgers \& Stratton, 2005). Marriage may have a smaller impact on the earnings of black than white husbands because the male-female wage gap is smaller among black than white workers (Burstein, 2007; Daniel, 1992). Concerning cohabitation, Daniel (1992) and Loh (1996) predict that cohabiting men will earn more than noncohabiters (but less than married men) because they devote more time to market work. On the other hand, if higher wages (or larger wage increases) make men more attractive as cohabiting partners, then the cohabitation differential will be at least partly due to selection.

Finally, the aforementioned explanations imply a marriage differential for unmarried fathers who later marry the mothers of their children. Nock (1998b) hypothesizes that by delaying or refusing marriage, some unmarried fathers avoid taking full responsibility for their children and do not comply with the social norms that tend to make married fathers work harder and longer. We could make a corollary argument about specialization. After marrying the mothers of their children, formerly unmarried fathers are able to specialize in market work more than their counterparts who remain single, which raises their wages.

Wives' characteristics may also affect her husbands' earnings differentials. Edin and Kefalas (2005) argue that some mothers are more likely to marry after they have established financial independence through steady employment and ownership of a car, a home, or both. Gassmen-Pines and Yoshikawa (2006) interpret experimental evidence of the long-term effects on marriage of New Hope-a program that increased employment and income among low-income unmarried mothers-as evidence in support of this hypothesis. After marriage, such mothers are less likely than nonworking mothers to specialize in home production while their husbands specialize in market work. Thus, transitions to marriage with steadily employed mothers should result in smaller earnings differentials for men than transitions to marriage with nonworking mothers (Chun \& Lee, 2001; Daniel, 1992; Loh, 1996)

Most researchers do acknowledge the possibility, however, that at least some proportion of these differentials reflects selection into marriage based on characteristics associated with earnings (such as health, mental health, and history of incarceration) that may or may not be observed (Nakosteen \& Zimmer, 1997).

\section{Empirical Work to Date on the Marriage Differential}

To identify the causal effect of marriage we must compare the future earnings of men who do not marry with the future earnings of equivalent men who do marry. While most researchers would agree that randomized experiments are the gold standard for causal inference, in practice, the statistical literature suggests that we can also identify some causal effects by controlling for all characteristics of the two groups, so-called confounding covariates, that are related to both the likelihood of marriage and the level of future earnings (Rubin, 1978). This paper presents analyses that attempt to identify the causal effect of marriage on earnings for a subpopulation of men. While we can never know for sure whether the required assumptions have been met for such identification, what we can do is to be clear about what those assumptions are so that the reader can assess their plausibility.

Early studies of the marriage differential used cross-sectional data and standard earnings equations with marital status dummy variables. Like the early crosssectional studies (see Hill, 1979), Ginther and Zavodny (2001) found that married men earned about 16 percent more than never-married men. They find no evidence of selection after controlling for premarital conceptions, which they argued increased the likelihood of marriage relative to men without such conceptions. Nock (1998b), focusing on fathers, controlled for premarital births, risky behavior, cognitive skills in some models, and sibling fixed effects in other models. His results suggest little evidence of selection on sibling-specific unobserved characteristics. More recently, 
Antonovics and Town (2004) attempted to control for selection using a crosssectional sample of monozygotic twins and found no evidence of selection on twinspecific unobserved characteristics.

Two studies explicitly modeled the process that selected some men into marriage. After estimating a standard earnings equation with a Heckman-type selection term, Nakosteen and Zimmer (1987) found no evidence of selection on unobserved variables. Chun and Lee (2001) used a switching regression model with an endogenous marital selection equation and two additional equations that accounted for wage penalties related to wives' labor hours (a proxy for specialization). Relying on restrictive assumptions about the covariance matrix, they also found no evidence of selection on unobserved variables.

Differencing (or fixed effects) models, the most widely recognized approach to date, use panel data (for example, the National Longitudinal Survey of Youth) to "difference out" unobservable characteristics that may predict both marital status and earnings. Typically, these results are then compared to cross-sectional results, with equivalence purportedly suggesting that there is no selection on unobservables. This approach does assume, however, that any unobserved confounders do not change over time. Moreover, without further assumptions, differenced estimates apply only to a subset of the population (the subset for whom marital status changed over the given time period), whereas cross-sectional analyses usually apply to the entire population that the sample represents. Therefore, these comparisons might be misleading.

Almost all studies that used differencing techniques to estimate the causal effect of marriage on earnings found minor support at best for the selection hypothesis (Korenman \& Neumark, 1991; Loh, 1996; Stratton, 2002). An exception, Cornwell and Rupert (1997) concluded that up to one-third of the total marriage differential observed in the cross-sectional data was due to selection. They attributed their unusual result to their use of a younger sample than Korenman and Neumark (1991), with more first marriages than divorces represented among those who experienced marital transitions.

Several studies found support for variations in the earnings differentials by race and union status. Hill (1979), Daniel (1992), Loh (1996), and Rodgers and Stratton (2005) found that the marriage differential for black men was lower than the marriage differential for white men. Daniel (1992) and Cohen (1999) found that black men had lower cohabitation differentials than white men. More generally, studies found that the marriage differential was larger than the cohabitation differential and, except for Stratton (2002), both differentials remained statistically significant after controlling for unobserved heterogeneity using individual or sibling fixed effects (Daniel, 1992; Loh, 1996). Finally, to test his hypothesis that unmarried fathers who postponed or refused marriage had lower earnings than other men, Nock (1998b) regressed earnings on the age at which unmarried fathers had their first child and several control variables that might select men into unmarried fatherhood. He found that men who fathered a child outside of marriage in their mid-20s had significantly lower earnings than childless men. However, this association became insignificant once he controlled for subsequent marriage or cohabitation.

\section{Contributions of Our Work to the Literature}

The objective of this study is to attempt to estimate the causal effect of transitions to marriage on earnings for unmarried fathers who are cohabiting or romantically involved with their child's mother. Using new data and methods, we improve on previous studies by: (1) focusing on an understudied population of men who are primarily racial-ethnic minorities and disadvantaged; (2) examining whether the marriage differential is greater for unmarried fathers with stronger partner bondscohabiters, the likely targets of the HMI; (3) investigating whether the marriage 
differential varies by racial-ethnic group; (4) controlling more exhaustively for selection bias and other threats to validity; and (5) isolating the effect of potential marriage on the earnings of unmarried fathers, rather than estimating the effect of marriage across the entire sample.

We operationalize these aims with a combination of refinements in both data and methods. First, to address aims (1) through (3) we use data from the richly detailed longitudinal Fragile Families and Child Wellbeing Study (FFCWS). This allows us to examine a population of relatively disadvantaged men who, though ignored in previous studies of the marriage differential, are now the primary targets of the HMI. The survey's racially/ethnically diverse cohort consists of 3,600 initially unmarried couples and their children. Some parents cohabit, while some have looser relationships. These features allow us to investigate subgroup differences between white, non-Hispanic black, and Hispanic fathers and between residential (cohabiters) and nonresidential (romantically involved) fathers. The relatively recent data reflect current conditions among a population that can be difficult to study due to its changing demographic characteristics.

We address aims (4) and (5) in two ways. First, the richness of the FFCWS data allows us to address selection bias by accounting for a myriad of confounding characteristics that have not typically been used in the previous literature. Besides the standard earnings equation variables, we have data on a broad array of health, family, and socioeconomic characteristics, and two structural variables concerning unemployment rates and child support enforcement. Further, we take advantage of the longitudinal nature of the FFCW data to properly control for the temporal ordering of birth, confounding covariates, marriage, and earnings. Second, we attack selection bias using several different methods. One of these approaches (the propensity score strategy) allows us to directly target a more relevant population when drawing conclusions about the likely impact of marriage.

Our results are consistent across varying sets of assumptions about the selection mechanism. In brief, using methods designed to address selection bias and applied to this relatively disadvantaged population, we are never able to reject the hypothesis that the effect of transitions to marriage on earnings, for any subgroup or overall, is zero. That is, there is not enough evidence to state with confidence that these effects differ from zero.

\section{DATA AND MEASURES}

\section{Data}

Our data came from the first four waves of the Fragile Families and Child Wellbeing Study (FFCWS) (Reichman et al., 2001). The FFCWS followed a cohort of 4,700 (3,600 nonmarital and 1,100 marital) newborns and their parents. The births occurred in 75 hospitals in 20 cities across the United States; the nonmarital births were representative of such births in large American cities (population greater than 200,000). Baseline data collection took place from spring 1998 through fall 2000. Follow-up interviews were conducted with both parents when the focal child was one, three, and five years of age.

Baseline interviews were available for 78 percent of eligible fathers and about 10 percentage points less than that at subsequent waves. Although the FFCWS obtained data from mothers about fathers, making missing data less problematic, not all mothers provided precise estimates of fathers' earnings. To address the issue of missing data, we use Multiple Imputation (MI) (Rubin, 1987; Schafer, 1997). MI is increasingly used to account for nonresponse in administrative and large-scale data sets-for example, the National Center for Health Statistics, the Department of Transportation, and the Federal Reserve Bank. MI uses observed data from study participants to replace missing values with imputed data that reflect both sampling 
uncertainty and uncertainty about the imputation model. These imputed values are used to construct several complete data sets (based on a prediction model). It is important to note that MI relies on weaker (that is, more plausible) assumptions about how the missing data came to be, as compared to complete case analysis (listwise deletion) and other standard approaches (Little \& Rubin, 2002). Sinkewicz (2006) provides a comparison of methods, including MI, which account for missing data in the FFCWS. Details about the scope of missing data in our study and our MI method are provided in Appendix C. ${ }^{1}$

\section{Measures}

This section provides a summary description of the variables in our analyses. A detailed, model-specific discussion of the temporal ordering of the variables is provided in the Methods section.

\section{Outcome Variable}

The primary outcome variable in this study is respondents' regular annual earnings for paid work in the year prior to the interview (informal earnings are not included in this measure). While both earnings and wages have been used as outcomes in previous studies, we use (the natural log of regular annual) earnings because many of the marriage-differential hypotheses have implications for both wages and hours worked. Although specialization, the hypothesis of primary interest to economists, is expected to affect wages, it is only one of several explanations for the marriage differential. Other hypotheses, such as social norms, social capital, and employer discrimination in favor of married workers, could explain why married men work more hours or weeks or why they have better employment opportunities than unmarried men. We also conducted analyses using employment as the outcome variable. The results, which are available upon request, are similar to those reported here.

\section{Potential Causal Variable, Marriage}

The causal variable of interest is the father's relationship status with the mother of the focal child, defined as: married, cohabiting, or romantically involved but not cohabiting with the mother of the focal child. At the baseline interview, all fathers in our sample were unmarried, although either cohabiting or romantically involved with the mother. We compare the earnings of fathers who subsequently transitioned to marriage with those who remained unmarried. We also make use of the cohabiting versus romantically involved distinction (resident versus nonresident) to perform subgroup analyses, as described in the Methods section.

\section{Confounding Covariates}

Our analyses attempt to explicitly control for a range of characteristics (hereinafter called confounding covariates) of the unmarried fathers (or the mothers of their children) that we hypothesize to be predictive of both the probability of getting married and subsequent earnings. We group these variables into three sets.

Set (A) includes variables that usually appear in standard earnings equations. These variables, which we derive from fathers' self-reports, include: a continuous measure

\footnotetext{
${ }^{1}$ All appendices are available at the end of this article as it appears in JPAM online. Go to the publisher's Web site and use the search engine to locate the article at http://www3.interscience.wiley.com/cgibin/jhome/34787.
} 
of age, along with age-squared, and age cubed; ${ }^{2}$ race-ethnic group (three categories: non-Hispanic white, non-Hispanic black, and Hispanic); ${ }^{3}$ education (four categories: less than high school, high school diploma or GED, some college, and college graduate); region of U.S. residence (four categories: Northeast, Midwest, South, or West) and dichotomous measures of nativity (whether the father is U.S. born) and additional training (government sponsored, vocational, technical, or military).

Set (B) confounders include additional self-reported fathers' characteristics. These variables fall into four categories: family characteristics, health and development, economic and social characteristics, and structural factors. Family characteristics include: number of children $(0,1$ or 2 , and 3 or more), multiple partner fertility (yes/no), father suggested an abortion (yes/no), and father's name is on the birth certificate of the focal child (yes/no). Health and development variables include: a dichotomous indicator of self-reported health (poor/good); a scale of depressive symptoms derived from the Center for Epidemiologic Studies of Depression (CES-D) (Radloff, 1977) (0 = low, 84 = high); drug and/or alcohol problems (yes/no); a scale measuring intelligence, derived from the Wechsler Adult Intelligence Scale-Revised (WAIS-R) (1981) $(0=$ low, $16=$ high); and a scale measuring the psychopathology of each of the father's parents $(0=$ low, $12=$ high $)$. Appendix $\mathrm{A}^{4}$ contains a comprehensive explanation of the depression scale, the indicator of drug/alcohol problems, the scale of parental psychopathology, and the intelligence scale. Economic and social characteristics include: continuous measure of regular annual earnings; continuous measure of informal/underground earnings; employment status (yes/no); car ownership - a proxy for wealth (yes/no); father provided prenatal cash or in-kind support; engagement in illegal activities, for example, stolen goods, drugs, or hustles (yes/no); incarceration history (yes/no); and a dichotomous measure of religiosity. Set (B) confounders also include two community-level variables: the city unemployment rate and an indicator of the strength of the child support enforcement policy in the state.

We measure all Set (B) variables at baseline, with two exceptions. Multiple-partner fertility and incarceration were not measured until the one-year follow-up survey. Both variables may have been influenced by the treatment (marriage) for those fathers who married in the first year, which would bias our results. At the same time, omitting these variables would represent a different source of bias. We decided that the latter was the more serious risk of bias, and therefore included these variables in our models. In the end, our analyses were robust to inclusion or exclusion of these variables.

Finally, Set (C) confounders are self-reported mothers' characteristics measured at baseline. They include: continuous measures of age and household income and dichotomous measures of car ownership, church attendance, employment in the past year, financial assistance from family, and financial assistance (public or private) with the birth. We also include an interaction between mother's report of household income and an indicator of whether she and the father were cohabiting at the time of report.

\section{METHODS}

The goal of our empirical analyses is to move from a comparison of differences in earnings across married and unmarried fathers, to an estimate of the potential effect

\footnotetext{
${ }^{2}$ Murphy and Welch (1990) show that a quartic polynomial in experience corrects the tendency of standard earnings equations, with quadratic expressions, to underpredict the growth in earnings for younger workers. We follow Card (1999), who shows that a cubic polynomial corrects a similar tendency for age-earnings equations to underpredict the growth in earnings for younger workers.

3 A fourth race-ethnicity category, "other," is excluded from the study because this small group of men is extremely heterogeneous across all relevant measures.

${ }^{4}$ All appendices are available at the end of this article as it appears in JPAM online. Go to the publisher's Web site and use the search engine to locate the article at http://www3.interscience.wiley.com/cgibin/jhome/34787.
} 
of transitions to marriage on the earnings of those fathers who remain unmarried. However, the problem with causal interpretations is that there may be unobserved differences between those who transition to marriage and those who do not, which drive differences in earnings.

We begin by replicating the cross-section and differencing methods predominant in the literature and incorporating the same types of variables available in previous studies. Then we investigate the potential efficacy of new methods to address selection. We build a bridge between the two methodological paradigms by exploring whether the unobserved variables implicitly controlled for in the differenced analyses are variables that we can control directly with our new data set. This section describes and compares the methods from the two paradigms.

\section{Traditional Paradigm: Standard Variables}

The most common methods used in the previous literature are cross-sectional analyses and fixed effects or differencing models. As typically used, these methods directly control for only standard earnings equation variables, so, analogously, we will use only those in Set (A). We use data from the third-year interview to create comparability between the causing variable in our cross-sectional and differenced methods and the analyses described in the next section.

\section{Cross-Sectional Model}

Our cross-sectional method simply fits regressions of the form

$$
\ln E_{i}=\alpha_{0}+\alpha_{x} X_{i}^{A}+\beta M_{i}+\varepsilon_{i}
$$

on the data from the third-year (post-birth) interview of the FFCWS, using the standard set of predictors (Set A). Here $i$ indexes individuals, $E_{i}$ is a measure of annual earnings, $X_{i}^{\mathrm{A}}$ denotes the standard confounding covariates in Set (A), and $M_{i}$ is the marital status indicator. To make causal inferences, the cross-sectional method that includes just the Set (A) covariates would require, among other assumptions (discussed below), that the variables in Set (A) comprise all confounding covariates. To examine sensitivity of the results to the missing data approach, we estimated both the cross-sectional and difference equations with both complete case and multiple imputation samples. The differences between these two strategies typically were not substantial and in no case altered statistical significance (results available upon request).

\section{Differenced Model}

Our second method, differencing, capitalizes on the panel data in the spirit of Korenman and Neumark (1991). We use data from both baseline and third-year interviews to estimate the coefficient of the marital status indicator variable, as in the following equation:

$$
\text { In } \Delta E i=\alpha_{x}^{\prime} \Delta X_{i}^{A}+\beta^{\prime} \Delta M_{i}+\varepsilon_{i}^{\prime}
$$

where $i$ indexes individuals, $\Delta E_{i}$ represents the change in annual earnings between baseline and year $3, \Delta X_{i}^{\mathrm{A}}$ denotes the change in the values of the standard confounding covariates (Set A) between baseline and year 3, and $\Delta M_{t}$ is the change in the marital status indicator variable between baseline and year 3 . The advantage of this method is that it has the potential to adjust for unobserved, individual-specific confounders that do not vary over this time period. 


\section{New Paradigm: New Variables and New Methods}

This section takes full advantage of the richness of FFCWS. Additionally, we explore the potential gains of using a semi-parametric modeling method-inverseprobability-of-treatment weighting with propensity scores.

\section{New Variables}

We explore the impact of taking advantage of the rich set of covariates available in FFCWS by comparing results from three groups of models that correspond to three arrays of confounding covariates $(\mathrm{A}, \mathrm{A}+\mathrm{B}, \mathrm{A}+\mathrm{B}+\mathrm{C})$.

\section{New Method: Inverse-Probability-of-Treatment Weighting Using the Propensity Score}

Given that the policy questions that motivate this research revolve around programs that attempt, in part, to support unmarried parents to transition to marriage, we focus on the potential effect of marriage on the earnings of those we observe to be unmarried three years post-birth (the so-called effect of the treatment on the controls). Implicitly, then, we want to compare the earnings of unmarried fathers who remain single to what their earnings would have been if they had transitioned to marriage. Since we cannot observe the counterfactual state (earnings if they had married), we compare these fathers to those who did transition to marriage but otherwise are similar to them on as many confounding covariates (those baseline characteristics that predict both the probability of marriage and subsequent earnings) as possible.

How does this work? First, define the propensity score for the $i$ th father in our sample as the probability that he transitioned to marriage between baseline and year 3, conditional on the full array of confounding covariates (Sets A, B, and C). Estimated propensity scores are then, in essence, a one-number summary of all of these covariates. Crucially, Rosenbaum and Rubin (1983) demonstrate that, assuming the propensity score model is correct, properly adjusting for the propensity score is sufficient to adjust for all the covariates used to create the propensity score. Therefore, if we have measured all confounding covariates, we should be able to unbiasedly estimate the targeted causal effect. This assumption of all confounders measured is commonly referred to in the sociology and economics literatures as selection on observables and in the statistics literature as ignorability of the assignment mechanism.

There are several different ways to control for estimated propensity scores, including matching, subclassification, and weighting. We chose to use inverseprobability-of-treatment weighting using propensity scores (Imbens, 2004; Kurth et al., 2006; Robins, 1999; Rosenbaum, 1987; Sato \& Matsuyama, 2003) to re-weight the group of fathers who transition to marriage so that, with respect to the values of the confounders, it mirrors the sample of fathers who do not. Henceforth we refer to this estimator as our weighted estimator. This approach has the same intuition as propensity-score matching; however, weighting is typically more efficient and also can be more stable in situations when the comparison group (married fathers) is smaller than the group about which we want to make inferences (unmarried fathers). Moreover, in this setting, weighting yielded better balance than matching.

To implement this strategy we first estimated propensity scores using probit regression (other models can also be used). Weights were constructed as follows: Unmarried fathers each received a weight of 1 , and married fathers each received a weight equal to $e(x) /[1-e(x)]$. This re-weights the comparison group (those fathers who are married either at year 1 or year 3 ) so that it mimics, in terms of observed confounding covariates, the original group of unmarried fathers in which we are interested. Again, assuming we have measured all confounders and our propensity score model is reasonable, our choice of weights can allow us to make inferences 
about what would have happened to the earnings of the group of fathers we observe to be unmarried still by year 3 if they had married.

The effectiveness of the weighting at creating similar groups can be checked by assessing the "balance" across groups. Specifically, we compared both the mean and standard deviation of each covariate between the group of unmarried men and the re-weighted comparison group of men who married between baseline and year 3 . The final propensity score model specification was chosen based on its ability to yield weighted groups that looked the most similar.

Finally, several studies have demonstrated that using a combination of propensity score weighting and regression is generally more effective at reducing bias than using either method on its own (Rubin, 1979; Rubin \& Thomas, 2000). Therefore, rather than calculating a simple difference in (weighted) mean outcomes, we ran a regression of the earnings at year 5 on all confounding covariates, $X_{i}^{\mathrm{ABC}}$ (measured at baseline), and the marriage indicator, $M_{i}$ (reflecting changes between baseline and year 3 ),

$$
\text { In } E_{i}=\alpha_{0}^{\prime \prime}+\alpha_{x}^{\prime \prime} X_{i}^{A B C}+\beta^{\prime \prime} M_{i}+\varepsilon_{i}
$$

in which the weights described above were incorporated as probability weights (similar to survey weights). We also ran standard (unweighted) regression models with the same confounding covariates used as predictors.

\section{Contrasting the Methods}

This section provides a comparison of the analytic methods used with respect to necessary assumptions and quantities estimated.

\section{Temporal Ordering of Variables}

Stark differences exist between analytic methods concerning the temporal ordering of the variables (described graphically in Appendix Figure E1 ${ }^{5}$ ). The differenced model attempts to identify causal effects by implicitly controlling for unobserved person-level confounding covariates that stay constant over time (from baseline to year 3). An undesirable property of this model, however, is that it may include (and thus adjust for) post-marriage variables as well (depending on the timing of the marriage for those fathers who got married). This may induce bias if these variables are also affected by marriage (Rosenbaum, 1984). For instance, if a given father got married one month after baseline and this marriage affected his subsequent training or educational attainment, which we then control for in our model, this can bias our causal estimates. The cross-sectional model uses data from only one time point (year 3) and thus suffers from a similar problem.

The new analytic methods take advantage of the longitudinal data to select measures that satisfy the temporal priority of the envisioned causal pathway. Therefore, confounding covariates (with two exceptions described above) are measured at baseline, the marriage indicator variable reflects the transition into marriage between baseline (when no one in our sample was married) and year 3, and the earnings outcome is measured at year 5 (the last year of our data).

\section{Parametric Form of the Model}

Even if the full set of variables represents all confounders, a linear model may be an inappropriate parametric specification (Rosenbaum \& Rubin, 1983, 1984). The

\footnotetext{
${ }^{5}$ All appendices are available at the end of this article as it appears in JPAM online. Go to the publisher's Web site and use the search engine to locate the article at http://www3.interscience.wiley.com/cgibin/jhome/34787.
} 
primary difference between linear regression and propensity score methods is the ability to loosen the parametric restrictions. Comparisons between (temporally separated) regression and propensity score results will yield some insight as to the importance of this key distinction.

The differenced method imposes even stronger parametric assumptions than non-differenced methods because the model assumes that the relationship between the covariates and the outcome is constant over time. This means that the coefficients on the time-varying coefficients would be expected to be the same across time periods. Moreover, this method can suffer from bias if the fathers who enter into marriage have different earnings trajectories, conditional on covariates included in the model, from those who do not-a scenario that could occur, for example, if marriage was induced by a random shock in earnings.

\section{What Is Being Estimated?}

Another key distinction across methods concerns the population about which we are able to make inferences. The propensity score method allows us to choose weights in such a way that we can generalize our inferences either to the treatment group, the control group, or the full sample (or the populations they represent). We focus on the effect we consider to be of greatest interest in this setting-what the effect of marriage would have been for those who did not initiate marriage within the first three years after the birth of their child (the so-called effect of the treatment on the controls). In contrast, the cross-section and regression approaches estimate effects across the entire sample of married and unmarried fathers (the average treatment effect). The differenced approach estimates the effect for those who get married within the first three years (the effect of the treatment on the treated) since it can only identify effects for those who had variation in their marital status variable across time points.

\section{Selection on Unobserved Versus Unobservable Variables}

One possible advantage of the differencing method is that it has the potential to control for unobserved characteristics of individuals that do not change over the given time period. Thus, differences between cross-sectional and differenced results are often considered evidence that selection on unobserved variables plays some role in the marriage earnings differential. ${ }^{6}$ It is unclear in this setting, however, if these characteristics are unobservable or merely typically unobserved in this literature. To investigate this question, we extend the standard cross-sectional and differenced earnings models (Equations 1 and 2) to control for the same sets of additional confounders used in the propensity score analyses. If estimates converge across these extended models, it suggests these additional confounders may be sufficient to identify the causal effect.

\section{Subgroup Analyses}

We investigate the possibility that the causal effect of marriage on earnings varies by key characteristics of the father. The literature on differences between cohabitation

\footnotetext{
${ }^{6}$ This comparison is not necessarily straightforward because, as noted above, the cross-sectional identifies the average treatment (marriage) effect while the differenced model identifies the effect only for the treated-in this case, those who transitioned into marriage between baseline and year 3. However, the consistency between our linear regression and propensity score estimates, which estimate the average treatment (marriage) effect and effect of the treatment (marriage) on the controls (unmarried), respectively, when conditioning on the full set of potential confounders, provides evidence that there are not any substantial differences between the effect of marriage on the unmarried versus the married.
} 
and marriage premiums (Daniel, 1992; Loh, 1996; Stratton, 2002) lead us to consider the relationship status of the unmarried fathers-cohabiting, and romantically involved but not cohabiting - as two different counterfactual states against which to compare the married state. In keeping with this, we conduct two sets of analyses. One set compares the married fathers to those who were cohabiting in years 1 and 3. Small cell size limitations, however, prevent us from separately estimating the differences between married fathers and those who were not cohabiting in years 1 or 3 . Therefore, the other set of analyses compares the married fathers to the full sample of fathers who are not married at years 1 or 3. Additionally, motivated by the work of Hill (1979), Daniel (1992), Loh (1996), and Rodgers and Stratton (2005), discussed above, we allow for different marriage effects across our three race-ethnic categories (white, non-Hispanic black, and Hispanic) by including interaction terms in all our analytic models.

\section{RESULTS}

\section{Summary Statistics}

Tables 1 and 2 provide descriptive data for the fathers in our analyses: the married fathers (the treatment group) and the two groups of unmarried fathers for which we estimate models - the full sample of unmarried fathers and the subsample of cohabiters only.

Table 1 presents summary statistics for our cross-section and difference methods. We see that fathers who marry by the year-3 interview differ in important ways from

Table 1. Descriptive statistics (mean/\%) for cross-section and differenced analyses.

\begin{tabular}{|c|c|c|c|}
\hline & $\begin{array}{c}\text { Married } \\
(N=582)\end{array}$ & $\begin{array}{l}\text { All Unmarried } \\
\quad(N=2,260)\end{array}$ & $\begin{array}{l}\text { Cohabiters } \\
(N=847)\end{array}$ \\
\hline \multicolumn{4}{|l|}{ Cross-sectional Analysis } \\
\hline \multicolumn{4}{|l|}{ Outcome Variable } \\
\hline Earnings & 23,731 & $18,636 * * *$ & $20,838 * * *$ \\
\hline \multicolumn{4}{|l|}{ Covariates (baseline) } \\
\hline Age & 27.1 & $26.4 * * *$ & 26.8 \\
\hline Race: White & 17.7 & $10.1 * * *$ & $11.5^{* * *}$ \\
\hline Black & 41.9 & $62.4 * * *$ & $52.0 * * *$ \\
\hline Hispanic & 40.4 & $27.5 * * *$ & $36.6 * * *$ \\
\hline U.S. born & 78.6 & $86.7 * * *$ & 80.0 \\
\hline Region: Northeast & 22.1 & $24.3 * * *$ & $26.8 * * *$ \\
\hline Midwest & 23.1 & $29.6 * * *$ & $26.4 * * *$ \\
\hline South & 37.9 & $33.7 * * *$ & $32.4 * * *$ \\
\hline West & 16.9 & $12.4 * * *$ & $14.6 * * *$ \\
\hline Education: $<$ high school & 27.9 & $36.0 * * *$ & $40.4 * * *$ \\
\hline High school/GED & 37.6 & $34.6 * * *$ & $32.3 * * *$ \\
\hline Some college & 29.7 & $27.2 * * *$ & $25.6 * * *$ \\
\hline College grad. & 4.9 & $2.2 * * *$ & $1.7 * * *$ \\
\hline Training & 58.1 & 56.8 & $51.6^{* * *}$ \\
\hline \multicolumn{4}{|l|}{ Differenced Analyses } \\
\hline \multicolumn{4}{|l|}{ Outcome Variable } \\
\hline Change in earnings & 5,200 & $3,662 * * *$ & $4158 * * *$ \\
\hline \multicolumn{4}{|l|}{ Covariates } \\
\hline Additional education & 16.4 & 16.2 & $12.2 * * *$ \\
\hline Additional training & 32.2 & $30.4 * * *$ & $25.5^{* * *}$ \\
\hline
\end{tabular}

Tests were conducted to determine whether there were statistically significant differences between married fathers vs. the full sample of unmarried fathers, and married fathers vs. the cohabiting fathers only: *** $p \leq 0.01 ; * * p \leq 0.05 ; * p \leq 0.10$. 
fathers who do not marry (compare column 1 to column 2), who, in turn, differ from the subsample of unmarried fathers who cohabit in years 1 and 3 (column 3 ). For example, at the year-3 interview, the annual earnings of fathers who marry $(\$ 23,731)$ are higher than those of unmarried fathers who cohabit in years 1 and 3 $(\$ 20,838)$, which, in turn, are higher than those of the full sample of fathers who remain unmarried $(\$ 18,636)$. Married fathers also have the advantage in terms of education; the proportion of unmarried fathers reporting some post-secondary schooling is about 6 percentage points less than the proportion of married fathers reporting some post-secondary schooling. A similar hierarchy holds for training. Married fathers are also slightly older on average. Further, there are noticeable race-ethnic differences: White fathers were about 18 percent of those who marry, but only 12 percent of those who cohabit in years 1 and 3 , and 10 percent of all fathers who remain unmarried. By contrast, black fathers are about 42 percent of those who marry but over 50 percent of those who cohabit in years 1 and 3 and over 60 percent of all fathers who remain unmarried. All of these characteristics are consistent with the higher earnings observed for married fathers.

Nevertheless, unmarried fathers are more likely to be U.S. born, more likely to live in the Northeast, and less likely to live in the South, which might imply higher earnings for unmarried fathers. Presumably, these effects would not be strong enough to counteract the opposite effects of characteristics such as educational attainment.

Table 2 presents summary statistics for our propensity score weighting method. Again, fathers who marry by their child's first or third birth year (column 1) have the highest earnings by their child's fifth birth year. However, even at baseline these fathers are also better off than those who do not marry on the same characteristics discussed above. For instance, these married fathers are less likely to be high school dropouts, and on average they are slightly older.

Table 2 also presents summary statistics for the fathers' characteristics in our extended models (Set B covariates). Importantly, we see that married fathers are earning more and are more likely to be employed even at baseline. Moreover, fathers who eventually marry are less likely to: father children by previous partners, want to abort the focal child, be ex-offenders, report substance abuse problems, or have experience with illegal employment. They are more likely to: report religiosity (church attendance), and own a car. These characteristics are generally consistent with the higher earnings observed among the married fathers.

Finally, Table 2 shows summary statistics for the mothers' characteristics in our extended models (Set C covariates). The mothers of children born to fathers who later marry these mothers are also better off than the mothers of children born to fathers who remain unmarried to these mothers. As compared with the latter, the former mothers are older, have higher incomes, and are more likely to own a car and report religiosity.

The patterns between cohabiters and the full sample of unmarried fathers in Table 2 are not as pronounced as those between married and unmarried fathers but, more often than not, the cohabiters appear to be slightly more advantaged. This is noticeable, for instance, with regard to the critical confounder "baseline earnings," as well as "car ownership," a proxy for wealth.

\section{TRADITIONAL ANALYSES: STANDARD VARIABLES}

Figure 1 displays the estimates of the effects of marriage on $(\ln )$ earnings at year 3 , disaggregated by race, for the traditional models (Appendix Table D $1{ }^{7}$ displays these

\footnotetext{
${ }^{7}$ All appendices are available at the end of this article as it appears in JPAM online. Go to the publisher's Web site and use the search engine to locate the article at http://www3.interscience.wiley.com/cgibin/jhome/34787.
} 
Table 2. Descriptive statistics (mean/\%) for regression and propensity score analyses.

\begin{tabular}{|c|c|c|c|}
\hline & $\begin{array}{l}\text { Married } \\
(N=665)\end{array}$ & $\begin{array}{l}\text { All Unmarried } \\
\quad(N=1,998)\end{array}$ & $\begin{array}{l}\text { Cohabiters } \\
(N=1,022)\end{array}$ \\
\hline \multicolumn{4}{|l|}{ Outcome Variable } \\
\hline Earnings & 27,940 & $19,928 * * *$ & $21,580 * * *$ \\
\hline \multicolumn{4}{|l|}{ Covariates (baseline) ${ }^{\mathrm{a}}$} \\
\hline Age & 27.1 & $26.4 * * *$ & $26.5 * * *$ \\
\hline Race: White & 16.6 & $9.9 * * *$ & $11.9 * * *$ \\
\hline Black & 42.7 & $64.9 * * *$ & $58.1 * * *$ \\
\hline Hispanic & 40.7 & $25.2 * * *$ & $30.0 * * *$ \\
\hline U.S. born & 77.6 & $88.7 * * *$ & $85.6 * * *$ \\
\hline Region: Northeast & 22.4 & $24.6 * * *$ & $26.1 * * *$ \\
\hline Midwest & 23.1 & $30.4 * * *$ & $29.5 * * *$ \\
\hline South & 37.6 & $33.5 * * *$ & $31.6 * * *$ \\
\hline West & 17.0 & $11.5 * * *$ & $12.8 * * *$ \\
\hline Education: $<$ high school & 39.6 & $46.1 * * *$ & $46.7 * * *$ \\
\hline High school/GED & 34.5 & 36.9 & $35.1 * * *$ \\
\hline Some college & 21.2 & $15.9 * * *$ & $17.1 * * *$ \\
\hline College grad. & 4.7 & $1.1 \% * *$ & 1.0 \\
\hline Training & 40.4 & 40.6 & 39.5 \\
\hline Children: Zero & 47.0 & $41.1 * * *$ & $40.8 * * *$ \\
\hline 1 or 2 & 48.2 & $52.6 * * *$ & $52.8 * * *$ \\
\hline 3 Plus & 3.8 & $6.3 * * *$ & $6.5 * * *$ \\
\hline Multiple partner fertility & 31.2 & $40.2 * * *$ & $37.6 * * *$ \\
\hline Father suggested abortion & 9.9 & $14.6 * * *$ & $12.5 * * *$ \\
\hline Father's name on birth cert. & 98.6 & $95.9 * * *$ & $97.2 * * *$ \\
\hline Bad health & 8.2 & 7.7 & 9.2 \\
\hline Depressive symptoms & 14.9 & $15.0 * *$ & 13.8 \\
\hline Alcohol or drug problems & 56.6 & $61.1 * * *$ & $60.8 * * *$ \\
\hline Mother's psychopathology & 0.5 & $0.6 *$ & $0.6 * * *$ \\
\hline Father's psychopathology & 0.7 & $0.7 * *$ & 0.7 \\
\hline IQ & 6.2 & 6.2 & $6.1 * *$ \\
\hline Father earnings & 18,528 & $14,619 * * *$ & $15,641 \div * *$ \\
\hline Father informal earnings & 1,157 & $1,452 * * *$ & $1,448 * * *$ \\
\hline Father owns car & 63.3 & 50.2 & $54.6 * * *$ \\
\hline Father gave prenatal support & 98.8 & $96.3 * * *$ & $98.1 * * *$ \\
\hline Father illegal activities & 2.6 & $5.1 * * *$ & $3.8 * * *$ \\
\hline Father's incarceration & 36.4 & $49.5 * * *$ & $41.2 * * *$ \\
\hline Father's religiosity & 30.7 & $23.0 * * *$ & $20.1 * * *$ \\
\hline Mother's age & 24.4 & $23.8 * * *$ & $23.8 * * *$ \\
\hline Mother's household income & 27,611 & $22,891 * * *$ & $24,052 \% * *$ \\
\hline Mother employed last year & 77.6 & 76.6 & 77.5 \\
\hline Financial assistance w/birth & 72.0 & $76.9 * * *$ & $75.6 * * *$ \\
\hline Family assistance for mother & 94.8 & 95.5 & 95.1 \\
\hline Mother owns car & 48.1 & $36.2 * * *$ & $39.9 * * *$ \\
\hline Mother's religiosity & 36.2 & $31.2 * * *$ & $28.2 * * *$ \\
\hline
\end{tabular}

Tests were conducted to determine whether there were statistically significant differences between married fathers vs. the full sample of unmarried fathers, and married fathers vs. the cohabiting fathers only: *** $p \leq 0.01 ; * * p \leq 0.05 ; * p \leq 0.10$. a All covariates measured at the baseline interview except multiple partner fertility and incarceration
measured at the 1-year interview.

results in tabular form). Solid circles and hollow triangles and the associated dark vertical lines correspond to estimates and 95 percent confidence bands from the cross-section and differenced models, respectively. Results in the left half of the figure are from models fit to the full sample (cohabiting and romantically involved). 


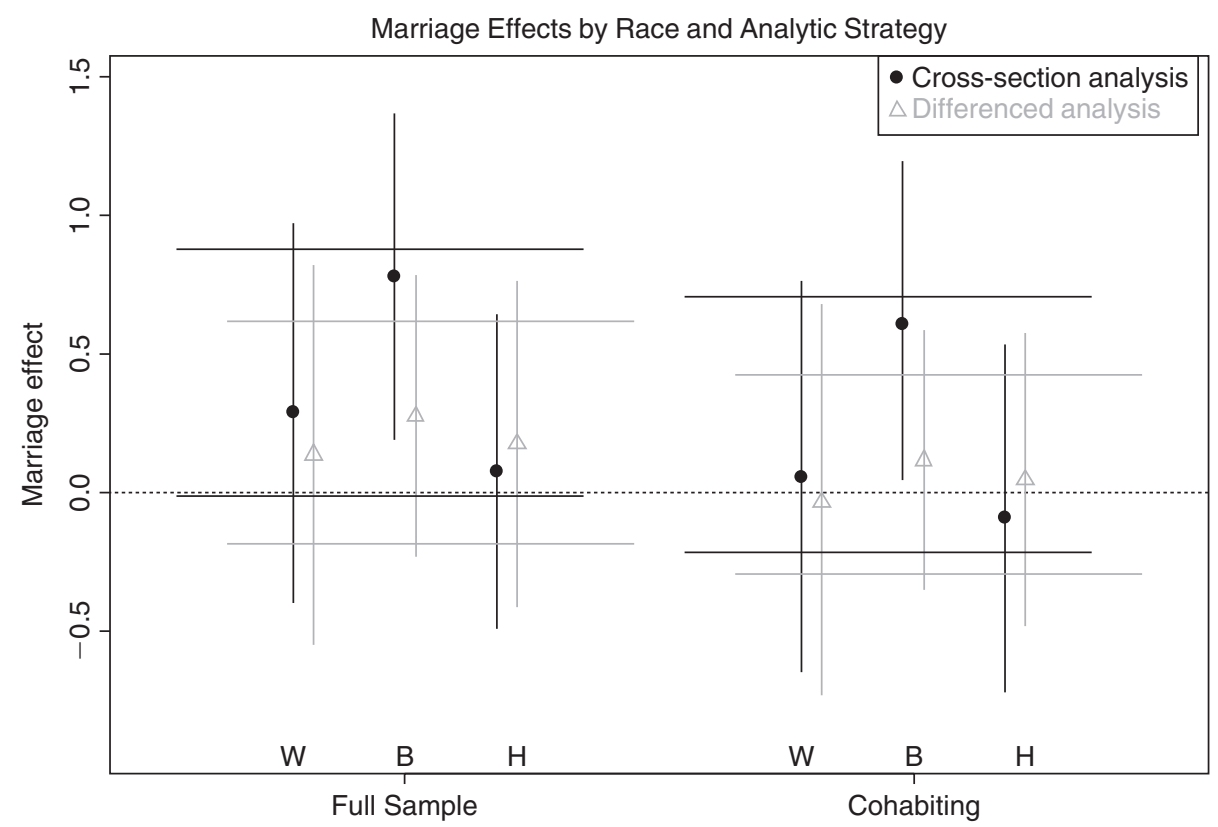

Figure 1. Effects of marriage on year 3 (log) earnings by race (WBH) for cross-section (dot) and difference (triangle) models. Differenced models reflect the change in log earnings between baseline and year-3 interviews. The full sample indicates both cohabiting and romantically involved fathers. $\mathrm{W}$ indicates white; $\mathrm{B}$ indicates black; $\mathrm{H}$ indicates Hispanic. Results from the cross-sectional analyses by race are displayed using circles for point estimates and dark solid lines for the 95 percent confidence intervals. Results from the differenced analyses by race are displayed using triangles for point estimates and light solid lines for 95 percent confidence intervals. The dark and light horizontal lines delineate the boundaries of the 95 percent confidence intervals for main effect estimates corresponding to the cross-section and differenced analyses, respectively.

Results in the right half of the figure are from models fit to the cohabiting subsample. Each pair of lines reflects marriage effects either for white (W), black (B), or Hispanic fathers $(\mathrm{H})$. Finally, the horizontal lines (dark for cross-section, light for differenced) reflect the bounds on 95 percent confidence intervals for the marriage estimates aggregated across race-point estimates were omitted to avoid further complicating the plot but can be assumed to be in the center of these intervals.

The fit of these models is quite poor. The $R^{2}$ for each of the two sets of crosssectional models is 0.07 and for the differenced models is barely above 0 . The poor fit for the differenced models probably occurs because these models drop important predictors such as race, age, region, and whether born in the U.S. from the analysis.

As shown in Figure 1, only two of the estimates across all analyses are statistically significant at a 5 percent significance level. These are the cross-section estimates of the effect of marriage on the earnings of the black fathers in our sample. They suggest an approximate gain in earnings of about 115 percent for the full sample and about 82 percent for the cohabiters, both of which seem unreasonably large. However, they are associated with large standard errors; thus, even in the absence of any effect, these estimates would have a higher probability than estimates with relatively low standard errors of having a more extreme magnitude. Moreover, the cross-section estimates are the ones we are least comfortable interpreting causally, given how few covariates were included, the lack of temporal separation, and the parametric constraints of the model. 


\section{New Methods: New Variables}

\section{Balance Checks}

As described above, a crucial step in implementing our propensity score weighting method is checking the balance that results between the group of unmarried fathers and the weighted group of married fathers. In the standard earnings model (Set A covariates), it was not difficult to obtain good balance in means; however, in the two expanded earnings models in Equation (3) we were not able to obtain balance that met our satisfaction. When we looked more closely at the group of unmarried fathers who consistently had propensity scores out of the range of the propensity scores for married fathers (our comparison group), we discovered that a substantial portion of these fathers (67) were unemployed, noncohabiting at baseline, and had been incarcerated at some point in their lives. Since only seven married fathers met these criteria, we felt there were an insufficient number of married fathers with these characteristics to serve as counterfactuals for the corresponding unmarried fathers. Removing these fathers created good balance in means across groups, as illustrated by the plots of standardized difference in means of confounding covariates displayed in the figures in Appendix $\mathrm{B}^{8}$ (results for comparisons of standard deviations were excellent but are not presented here).

We believe that this finding is important in and of itself. That so few of these unemployed, noncohabiting fathers reporting a record of incarceration end up married means that it is probably very difficult to assess the effect of marriage on the earnings of these fathers using observational data. Moreover, this finding points to inherent problems in conventional linear regression models that would extrapolate over areas where data are nonexistent or, at best, limited. Propensity score approaches have the capacity to identify and avoid this problem.

\section{Analysis Results}

The results from the standard linear regression (dots) and propensity score weighted (triangles) models, displayed in Figure 2, again are disaggregated by race-ethnic group and use the natural log of earnings, this time at year 5 , as the dependent variable (Appendix Table D2 ${ }^{9}$ displays these same results in tabular form). However, this plot reflects the results of our regression and weighted methods rather than our earlier cross-section and difference methods. Moreover, the six pairs of estimate/confidence interval combinations (three race-ethnic groups by two methods) are now replicated twice in each sample. The two replications correspond to the two additional sets of confounding covariates included in the extended earnings models. Once again, the horizontal lines (dark for linear regression and light for the weighted) reflect the bounds on 95 percent confidence intervals for the marriage effect estimates aggregated across race), here based on the full array of confounders (Sets A, B, and C).

Recall that the propensity score weighted and regression estimates target effects for different groups of individuals. The fact that these corresponding estimates are generally quite similar across these methods lends support to the hypothesis that the average effect of marriage across the whole sample of married and unmarried fathers (after excluding the "unmatchable fathers") is similar (if not equivalent to) the effect of marriage on the unmarried.

\footnotetext{
${ }^{8}$ All appendices are available at the end of this article as it appears in JPAM online. Go to the publisher's Web site and use the search engine to locate the article at http://www3.interscience.wiley.com/cgibin/jhome/34787.

${ }^{9}$ All appendices are available at the end of this article as it appears in JPAM online. Go to the publisher's Web site and use the search engine to locate the article at http://www3.interscience.wiley.com/cgibin/jhome/34787.
} 


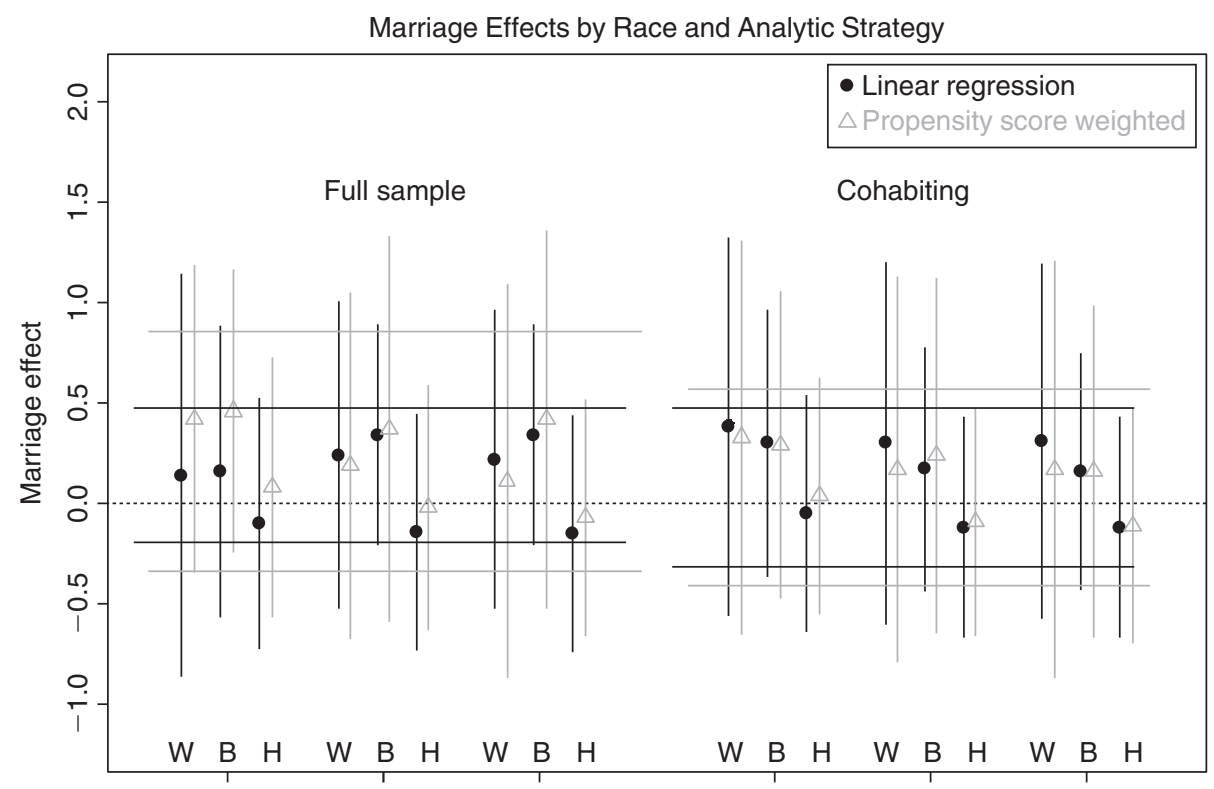

$\begin{array}{lll}\text { (A) standard } & \text { (B) }+ \text { dad } & \text { (C) }+ \text { mom }\end{array}$

(A) standard (B) + dad

(C) + mom

Figure 2. Effects of marriage on year-5 (log) earnings by race (WBH) for regression (dot) and propensity score (triangle) strategies. Full sample indicates both cohabiting and romantically involved fathers. $\mathrm{W}$ indicates white; $\mathrm{B}$ indicates black; $\mathrm{H}$ indicates Hispanic. Standard indicates standard earnings variables (Set A); + dad indicates the addition of previously unobserved father characteristics (Set B) to Set $(\mathrm{A})$; + mom indicates the addition of previously unobserved mother characteristics (Set C) to Sets (A) and (B). Results from the linear regression analyses by race are displayed using circles for point estimates and dark solid lines for the 95 percent confidence intervals. Results from the propensity score weighted analyses by race are displayed using triangles for point estimates and light solid lines for 95 percent confidence intervals. The dark and light horizontal lines delineate the boundaries of the 95 percent confidence intervals for main effect estimates from the full model corresponding to the linear regression and weighted analyses, respectively.

As measured by $R^{2}$, the fit of the propensity score weighted models is nearly identical to the fit of the regression models; for example, using the full set of predictors, the $R^{2}$ is 0.17 and 0.16 (full sample and cohabiters, respectively) for the weighted models compared to 0.16 and 0.17 , respectively, for the linear regression models.

The direction of the estimates is positive for white and black fathers, and negative for Hispanic fathers. However, none of the marriage effect estimates from the linear regression or weighted analyses for any race-ethnic group, based on either the full sample or the cohabiting subsample, is statistically significantly different from zero. Thus, we cannot reject the hypothesis of no effect of marriage on earnings for any subgroup or overall. This may be because of large standard errors or simply because there is no causal link. We cannot distinguish between these possibilities in this study. We see a similar ordering of magnitude of marriage effects across race-ethnic groups across all covariate sets. The effect size is about the same for white and black fathers while it is smaller for Hispanic fathers. However, the differences between these estimates are not statistically significant.

\section{Building a Bridge: Controlling for Unobserved or Unobservable Variables?}

Here we examine the impact of expanding our initial cross-section and difference analyses (as before, using data from the year 3 or both baseline and year 3 , 


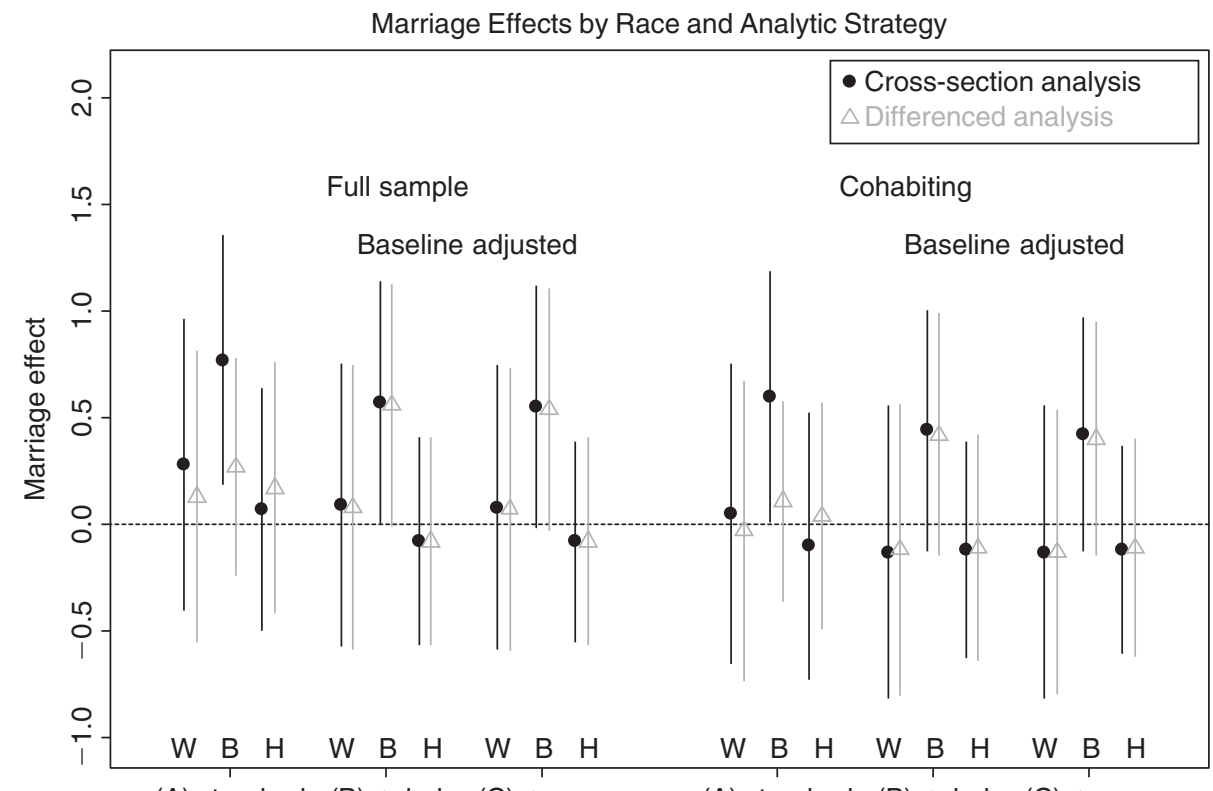

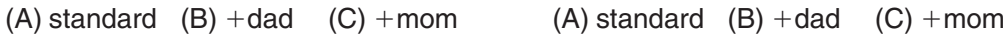

Figure 3. Impact of adjustment for additional baseline confounding covariates on crosssection (dot) and difference (triangle) estimates of the effect of marriage on year-3 (log) earnings. Full sample indicates both cohabiting and romantically involved fathers. W indicates white; B indicates black; $\mathrm{H}$ indicates Hispanic. Standard indicates standard earnings variables (Set A); + dad indicates the addition of previously unobserved father characteristics (Set B) to Set (A); + mom indicates the addition of previously unobserved mother characteristics (Set C) to Sets (A) and (B).

respectively) to include the two sets of typically unobserved confounders-fathers' characteristics (Set B) and mothers' characteristics (Set C) measured at baseline.

The results from the augmented cross-sectional and differenced methods are displayed in Figure 3 (Appendix Table D $3^{10}$ displays them in tabular form). The form of the display is otherwise analogous to the display in Figure 2. However, in Figure 3 the results are again from cross-section and differenced models.

First, the fit of the models, as measured by $R^{2}$, increases dramatically once we include these additional predictors. After including Set (B) predictors, the crosssection model has an $R^{2}$ of 0.15 for the full sample and 0.17 for the cohabiters; after adding Set (C) predictors, this $R^{2}$ changes, for the cohabiting sample only, to 0.18. For either expanded sets of predictors, the $R^{2}$ for the differenced model jumps to 0.38 for the full sample and 0.43 for the cohabiters.

The results displayed in Figure 3 are striking. While Figure 1 indicates that the cross-section and difference estimates are not particularly close when we include only the standard earnings covariates (Set A) or their change in the difference models, conditioning on the additional confounders (Sets B and C), as seen in the second and third as well as the fifth and sixth interval groupings, leads to virtually identical point estimates in the cross-section and difference models. Note that even though the standard errors are relatively large for these estimates, this is not relevant to the

${ }^{10}$ All appendices are available at the end of this article as it appears in JPAM online. Go to the publisher's Web site and use the search engine to locate the article at http://www3.interscience.wiley.com/cgibin/jhome/34787 
comparison. When we make comparisons between, for instance, different estimated marriage effects for different race-ethnicities, the standard error is a relevant benchmark because the goal is to distinguish between true differences in the population quantities these effects are trying to estimate. In this case, however, we are just trying to ascertain if these methods would yield the same estimate for this sample. These results lead us to believe that the unobserved variables for which the differencing method adjusts are actually observed in the sets of extra variables we are able to include from the FFCWS.

Moreover, the fact that the difference estimates change more dramatically than the cross-section estimates suggests that the assumption of similar earnings trajectories in the absence of marriage between men who marry and those who do not may only hold after conditioning on these extra variables-this appears to be particularly true for the black fathers. Thus, the differenced model may be less robust than previously assumed. These results provide support for the expanded earnings models in the propensity score and associated regression methods (Figure 2) that incorporated these additional variables.

\section{CONCLUSION}

Recent legislation that provides funds to support Building Strong Families, a Healthy Marriage Initiative demonstration project targeting unwed parents, has focused new attention on an old question: Does marriage have a causal effect on men's earnings? Potential answers to the "marriage differential" puzzle lie in sociological theories of gender-role differentiation or economic theories about specialization. According to these theories, the earnings of married men increase relative to the earnings of unmarried men because marriage creates opportunities and pressures, both from within and from without the family, for men to work harder or more intensely. For example, employers may discriminate in favor of married men. Financial support from wives or from the friends and relatives of wives (as well as job leads or recommendations) may enable married men to obtain better jobs or higher wages than unmarried men.

Traditionally, testing these hypotheses has been difficult because unobservable characteristics that select men into marriage could also explain the marriage differential. Differencing out these unobservable characteristics is the predominant approach used to address the selection problem in the economics literature, although a few studies have tried to model the process that selects men into marriage. We approached the selection problem with a variety of tools and a different source of data on a more policy-relevant group of men.

Our cross-sectional point estimates of the marriage differential are on the same order of magnitude as previous cross-sectional estimates, but are statistically significant only for black unmarried fathers. Consistent with the hypothesis that selection plays some role, our point estimates of the marriage differential for white, black, and Hispanic unmarried fathers decline when we difference out and condition on variables that are unobservable in most studies, or use propensity scores to take account of selection into marriage. Further, regardless of the method we use to account for selection (ignoring the cross-section models, which were not designed to deal with selection), there is not enough evidence to support the claim that marriage has a non-zero effect on the earnings of unmarried fathers. Also, while at face value the estimates across racial-ethnic groups and cohabitation status appear to be different, these estimates are not statistically significantly different from each other. However, they suggest that these types of subgroup analyses may still be important in future analyses where the sample sizes may be big enough to detect such differences.

Our inability to reject the null hypothesis of no effect of marriage could be because the effect really is negligible, because our estimates are too imprecise to distinguish the effect from zero, or because we have not been able to sufficiently 
control for selection bias. However, conditioning on variables that are unobservable in most studies does at least substantially improve the fit of all the models examined. This suggests that the vast majority of the variation in the earnings of unmarried fathers is not explained by marriage or the characteristics most likely to be measured in conventional data sets. That the point estimates in the propensity score and associated regression models are substantially smaller than the point estimates in the cross-sectional and differenced models also suggests that differencing, the predominant approach used to address selection, may actually lead to biased estimates of the marriage differential.

The biggest contribution to reducing selection bias appears to be from the inclusion of the new variables in the estimation models. It is difficult to gauge the impact of properly accounting for the temporal ordering of the variables, though we also believe it to be a crucial component of our new analytic strategy. Our work provides some evidence that it may be possible to measure all of the previously unobserved variables captured by the fixed effects models. Moreover, it suggests that the assumptions underlying the differenced and fixed effects methods used in the past may not have been met with previous data. On the other hand, our results appear to be robust to the model specification (propensity score vs. a linear model) and the choice of quantity being estimated (treatment effect for the whole sample vs. just the unmarried men).

Finally, our propensity score sample excludes unemployed/noncohabiting/formerly incarcerated fathers because we could not find a sufficiently large group of married fathers in our data with similar characteristics. Due to the lack of empirical counterfactuals, we are unable to estimate the effect of marriage on these fathers with any confidence. Moreover, the empirical evidence suggests their probability of getting married is small. Thus, there are likely to be more effective strategies for raising earnings for this particular group of fathers than marriage promotion. Future studies will need to consider whether there are sufficient data to make convincing inferences for highly disadvantaged populations of fathers.

In sum, we conclude that even if BSF increases marriage rates and the sustainability of those marriages, it is not clear that it would, in turn, result in higher earnings for the fathers these programs are most likely to target. We will have to await results from randomized experiments that evaluate BSF and other similar interventions to see whether marriage can indeed be induced (or relationships strengthened) and whether, in practice, such transitions translate into real changes in work and earnings.

RONALD MINCY is Maurice V. Russell Professor of Social Policy and Social Work Practice at Columbia University, School of Social Work.

JENNIFER HILL is an Associate Professor of Applied Statistics at New York University, Department of Humanities and Social Sciences, The Steinhardt School of Culture, Education, and Human Development.

MARILYN SINKEWICZ is an Assistant Professor at University of Michigan, School of Social Work.

\section{ACKNOWLEDGMENTS}

The authors thank Paula England, Irwin Garfinkel, Jane Waldfogel, Shoshona Grossbard, Felicity Skidmore, and participants at several colloquia for their comments on an earlier draft. An earlier version of this manuscript was presented at the MacArthur Network on Family and the Economy, and the Institute for Research on Poverty, University of Wisconsin. Funding for the development of the multiple imputation samples was provided by grants from the Ford Foundation and the Annie E. Casey Foundation. The Fragile Families and Wellbeing study was made 
possible by the generous financial support of the National Institute of Child and Human Development (NICHD; grant number R01HD36916) and a consortium of private foundation and government agencies identified at http://crew.princeton.edu/ fragilefamilies/funders.asp.

\section{REFERENCES}

Aguilera, M. B. (2003). The impact of the worker: How social capital and human capital influence the job tenure of formerly undocumented Mexican immigrants. Sociological Inquiry, 73, 52-83.

Aguilera, M. B. (2008). Personal networks and the incomes of men and women in the United States: Do personal networks provide higher returns for men or women? Research in Social Stratification and Mobility, 26, 221-233.

Amato, P. R. (2007). Strengthening marriage is an appropriate social policy goal. Journal of Policy Analysis and Management, 26, 952-955.

Antonovics, K., \& Town, R. (2004). Are all the good men married? Uncovering the sources of the marital wage premium. American Economic Review 94, 317-321.

Bartlett, R., \& Callahan, C. (1984). Wage determination and marital status: Another look. Industrial and Labor Relations Review, 23, 90-96.

Becker, G. S. (1965). A theory of the allocation of time. Economic Journal, 75, 493-515.

Becker, G. S. (1973). A theory of marriage: Part I. Journal of Political Economy, 81, 813-846.

Becker, G. S. (1981). A treatise on the family, 1st ed. Cambridge: Harvard University Press.

Burstein, N. R. (2007). Economic influences on marriage and divorce. Journal of Policy Analysis and Management, 26, 11-30.

Card, D. (1999). The causal effects of education on earnings. In O. Ashenfelter \& D. Card (Eds.), Handbook of labor economics, Vol. 5 (pp. 1801-1863). Amsterdam: North Holland.

Carlson, M., Garfinkel, I., McLanahan, S., Mincy, R., \& Primus, W. (2004). The effects of welfare and child support policies on union formation. Population Research and Development Review, 23, 513-542.

Carlson, M., McLanahan, S., \& England, P. (2004). Union formation in fragile families. Demography, 41, 237-262.

Chun, H., \& Lee, I. (2001). Why do married men earn more: Productivity or marriage selection? Economic Inquiry, 39, 307-319.

Cohen, P. N. (1999). Racial-ethnic and gender differences in returns to cohabitation and marriage: Evidence from the Current Population Survey. U.S. Census Bureau Population Division Working Paper 35.

Coleman, J. S. (1988). Social capital in the creation of human capital. American Journal of Sociology, 94, S95-120.

Cornwell, C., \& Rupert, P. (1997). Unobservable individual effects: Marriage and the earnings of young men. Economic Inquiry, 35, 285-294.

Daniel, K. (1992). Does marriage make men more productive? Population Research Center Discussion Paper No. 92-2. Chicago: University of Chicago.

Dion, M. R., Devaney, B., McConnell, S., Ford, M., Hill, H., \& Winston, P. (2003). Helping unwed parents build strong and healthy marriages: A conceptual framework for interventions. Doc. No. PR03-02. Washington, DC: Mathematica Policy Research, Inc..

Edin, K., \& Kefalas, M. (2005). Promises I can keep: Why poor women put motherhood before marriage. Berkeley: University of California Press.

Fossett, M. A., \& Kiecolt, K. J. (1993). Mate availability and African American family structure in the U.S. nonmetropolitan South, 1960-1990. Journal of Marriage and Family, 55, 288-302.

Furstenberg, F. F. (2007). Should government promote marriage? Journal of Policy Analysis and Management, 26, 956-960.

Gallagher, M. (2003). The marriage gap: How and why marriage creates wealth and boosts the well-being of adults. In O. Clayton, R. B. Mincy, \& D. Blankenhorn (Eds.), Black fathers 
in contemporary American society: Strengths, weaknesses, and strategies for change (pp. 71-83). New York: Russell Sage Foundation.

Gassman-Pines, A., \& Yoshikawa, H. (2006). Five-year effects of an anti-poverty program on marriage among never-married mothers. Journal of Policy Analysis and Management, 25, 11-30.

Ginther, D. K., \& Zavodny, M. (2001). Is the male marriage premium due to selection? The effect of shotgun weddings on the return to marriage. Journal of Population Economics, $14,313-328$.

Harknett, K., \& McLanahan, S. (2004). Racial and ethnic differences in marriage after the birth of a child. American Sociological Review, 69, 790-811.

Hill, M. (1979). The wage effects of marital status and children. Journal of Human Resources, 14, 579-594.

Imbens, G. (2004). Nonparametric estimation of average treatment effects under exogeneity: A review. Review of Economics and Statistics, 86, 4-29.

Kanter, R. M. (1993). Men and women of the corporation. New York: Basic Books.

Kenny, L.W. (1983). The accumulation of human capital during marriage by males. Economic Inquiry, 21, 223-231.

Korenman, S., \& Neumark, D. (1991). Does marriage really make men more productive? Journal of Human Resources, 26, 282-307.

Kurth, T., Walker, A. M., Glynn, R. J., Chan, K. A., Gaziano, J. M., Berger, K., \& Robins, J. M. (2006). Results of multivariable logistic regression, propensity matching, propensity adjustment, and propensity-based weighting under conditions of non-uniform effect. American Journal of Epidemiology, 163, 262-270.

Lichter, D. T., LeClere, F. B., \& McLaughlin, D. K. (1991). Local marriage markets and the marital behavior of black and white women. American Journal of Sociology, 96, 843-867.

Lichter, D. T., McLaughlin, D. K., Kephart, G., \& Landry, D. J. (1992). Race and the retreat from marriage: A shortage of marriageable men? American Sociological Review, 57, 781-799.

Little, R. J. A., \& Rubin, D. B. (2002). Statistical analysis with missing data, 2nd ed. New York: John Wiley.

Loh, E. S. (1996). Productivity differences and the marriage wage differential for white males. Journal of Human Resources, 31, 566-589.

Mincer, J. (1962). Labor force participation of married women: A study of labor supply. In H. G. Lewis (Ed.), Aspects of labor economics (pp. 63-106). Princeton: Princeton University Press.

Mincy, R. (1994). Strengthening fragile families: A proposed grantmaking initiative. New York: Ford Foundation.

Mincy, R., \& Dupree, A. (2001). Welfare reform, child support, and family formation. Children and Youth Services Review, 23, 577-601.

Mincy, R., \& Pouncy, H. (1997). Paternalism, child support enforcement, and fragile families. In L. Mead (Ed.), The new paternalism: Supervisory approaches to poverty reduction (pp. 130-160). Washington, DC: Brookings Institution Press.

Murphy, K., \& Welch, F. (1990). Empirical age-earnings profiles. Journal of Labor Economics, 8, 202-239.

Nakosteen, R. A., \& Zimmer, M. A. (1987). Marital status and earnings of young men: A model with endogenous selection. Journal of Human Resources, 22, 248-268.

Nakosteen, R. A., \& Zimmer, M. A. (1997). Men, money, and marriage: Are high earners more prone than low earners to marry? Social Science Quarterly, 78, 66-82.

Neckerman, K. M., \& Fernandez, R. M. (2003). Keeping a job: Network hiring and turnover in a retail bank. Research in the Sociology of Organizations, 20, 299-318.

Nock, S. L. (1998a). Marriage in men's lives. New York: Oxford University Press.

Nock, S. L. (1998b). The consequences of premarital fatherhood. American Sociological Review, 63, 250-263. 
Papanek, H. (1973). Men, women, and work: Reflections on the two-person career. American Journal of Sociology, 78, 852-872.

Parsons, T. (1943). Age and sex in the social structure of the United States. American Sociological Review, 7, 604-616.

Parsons, T. (1949). The social structure of the family. In R. N. Anshen (Ed.), The family: Its function and destiny (pp. 173-201). New York: Harper.

Radloff, L. S. (1977). The CES-D scale: A self-report depression scale for research in the general population. Applied Psychological Measurement, 1, 385-401

Reichman, N. E., Teitler, J. O., Garfinkel, I., \& McLanahan, S. S. (2001). Fragile families: Sample and design. Children and Youth Services Review, 23, 303-326.

Robins, J. M. (1999). Association, causation, and marginal structural models. Synthese, 121, 151-179.

Rodgers, W., \& Stratton, L. S. (2005). The male marital wage differential: Race, training, and fixed effects. Institute for the Study of Labor (IZA), Discussion Paper No. 1745.

Rosenbaum, P. R. (1984). The consequences of adjustment for a concomitant variable that has been affected by the treatment. Journal of the Royal Statistical Society, Series A, 147, 656-666.

Rosenbaum, P. R. (1987). Model-based direct adjustment. Journal of the American Statistical Association, 82, 387-394.

Rosenbaum, P. R., \& Rubin, D. B. (1983). The central role of the propensity score in observational studies for causal effects. Biometrika, 70, 41-55.

Rosenbaum, P. R., \& Rubin, D. B. (1984). Reducing bias in observational studies using subclassification on the propensity score. Journal of the American Statistical Association, 79, 516-524.

Royston, P. (2004). Multiple imputation of missing values. Stata Journal, 4, 227-241.

Rubin, D. B. (1978). Bayesian inference for causal effects: The role of randomization. The Annals of Statistics, 6, 34-58.

Rubin, D. B. (1979). Using multivariate matched sampling and regression adjustment to control bias in observational studies. Journal of the American Statistical Society, 74, 318-328.

Rubin, D. B. (1987). Multiple imputation for nonresponse in surveys. New York: Wiley.

Rubin, D. B., \& Thomas, N. (2000). Combining propensity score matching with additional adjustments for prognostic covariates. Journal of the American Statistical Association, 95, 573-585.

Sato, T., \& Matsuyama, Y. (2003). Marginal structural models as a tool for standardization. Epidemiology, 14, 680-686.

Schafer, J. L. (1997). Analysis of incomplete multivariate data. London: Chapman \& Hall.

Sinkewicz, M. (2006). The mental health of men: Profiles and life trajectories of urban American fathers. Unpublished doctoral dissertation, Columbia University School of Social Work.

South, S. J., \& Lloyd, K. M. (1992). Marriage opportunities and family formation: Further implications of imbalanced sex ratios. Journal of Marriage and the Family, 54, 440-451.

Stratton, L. (2002). Examining the wage differential for married and cohabiting men. Economic Inquiry, 40, 199-212.

Thomas, A., \& Sawhill, I. (2002). For richer or for poorer: Marriage as an antipoverty strategy. Journal of Policy Analysis and Management, 21, 587-599.

van Burren, S., Boshuizen, H. C., \& Knock, D. L. (1999). Multiple imputation of missing blood pressure covariates in survival analysis. Statistics in Medicine, 18, 681-696.

Wechsler, D. (1981). WAIS-R Manual: Wechsler Adult Intelligence Scale-Revised. New York: Harcourt Brace Jovanovich.

Wilson, W. J. (1987). The truly disadvantaged: The inner city, the underclass and public policy. Chicago: University of Chicago Press. 


\section{APPENDIX A: DESCRIPTION OF SELECTED COVARIATES}

\section{Depression Scale}

An abbreviated version of the Center for Epidemiologic Studies Depression (CES-D) is used to create a depression scale $(0=$ low, $84=$ high $)$. The CES-D is designed to measure the frequency of depressive symptoms previously identified in the clinical literature on depression as well as in other depression inventories (Radloff, 1977). The shortened version of the CES-D contains 12 items that correspond to two emotional components-depressed mood and psychomotor retardation. These questions pertain to symptoms of depression experienced over the past week. They include: (1) feeling bothered, (2) poor appetite, (3) feeling blue, (4) lack of focus, (5) feeling depressed, (6) feeling like everything is an effort, (7) feeling fearful, (8) trouble sleeping, (9) talking less than usual, (10) feeling lonely, (11) feeling sad, and (12) feeling like one cannot get going.

\section{Alcohol/Drug Problems}

A dichotomous measure of drug and alcohol problems is constructed from five indicators that reflect the extent to which fathers engage in substance abuse: (1) consumed three or more drinks on the same day in the past three months; (2) reported alcohol use in the past month-every day, several times per week, or several times per month; (3) reported drug use in the past month-every day, several times per week, or several times per month; (4) reported that drinking or drug use interfered with work or personal relationships in the past year; and (5) sought help or treatment for drug or alcohol problems. The measure of alcohol and drug problems is scored yes if the father replies affirmatively to any one of the five indicators described above.

\section{Parental Psychopathology}

History of parental psychopathology is assessed for both the father's father and the father's mother. A continuous measure is constructed from a battery of questions asked retrospectively of Fragile Families men about their parents. The questions, derived from the National Comorbidity Study, concern the respondent's father's and mother's histories of depression, anxiety, alcohol use, drug use, and suicide. Responses to these questions are simply summed, producing a scale from 0 (no affirmative answers to any of the questions) to 12 (affirmative responses to all questions).

\section{Intelligence Scale}

An assessment of IQ is derived from the WAIS-R. The word association questions provide a proxy for the respondent's intelligence quotient. The full WAIS-R contains 11 separate tests grouped into performance and verbal scales. The subtest on similarities is used to determine vocational ability, to assess adult intellectual ability in the classroom, and to determine organic deficits. The Fragile Families and Child Wellbeing Study includes an abbreviated form of the similarities subtest and asks 8 of 10 word association questions. The father's answers to the 8 questions are summed in accordance with published documentation to construct a scale from 0 to 16 . 


\section{APPENDIX B: BALANCE DIAGNOSTICS}

The following figures provide a display of the greater balance achieved through propensity-score weighting, Figure B1 for the full sample and Figure B2 for cohabiters only. For each covariate listed on the left we display the standardized difference in means ${ }^{11}$ corresponding to each method-no weighting (open circles) and weighting (solid dots) - and for each imputed data set (separate symbol for each). Some of the variables have been redefined so that (with the exception of multiple indicators that represent a multi-category variable such as race) more positive values of the covariate are associated with higher earnings-for instance, the indicator for "bad health" was redefined as an indicator for "no bad health."
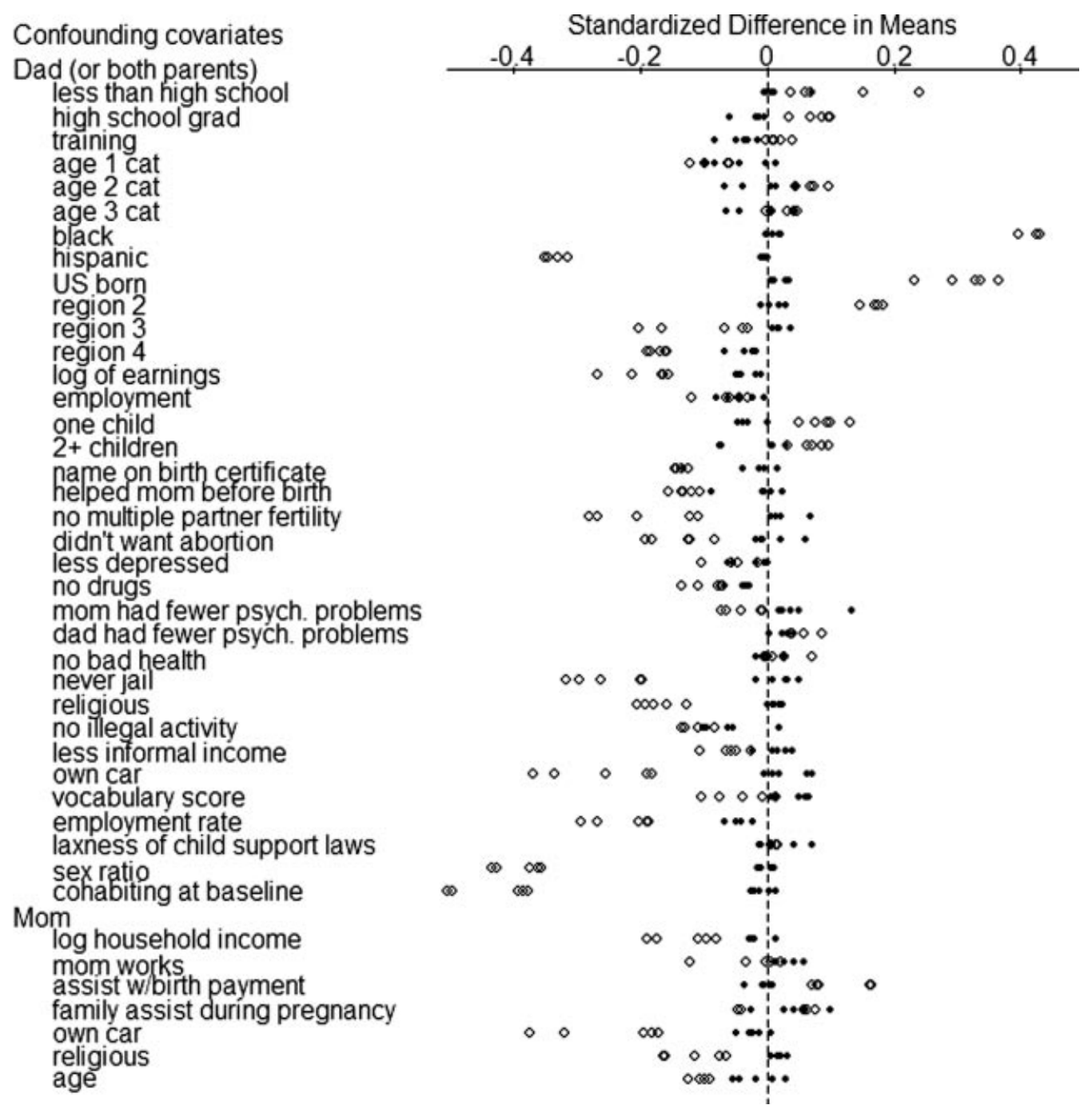

Figure B1. Standardized difference in means for each covariate from Model 5 for both weighted (solid dots) and unweighted (open circles) approaches, displayed as a separate value for each imputed data set. This figure corresponds to the full sample.

${ }^{11}$ Where the standardized difference in means is defined as the difference in sample means between the married ( $\mathrm{t}$ ) and unmarried (c) groups divided by the standard deviation in the unmarried group: $\$ \$$. 
It is easy to discern from these figures that the weighting noticeably improved the balance in means across the "treatment" (married versus unmarried) groups, particularly with regard to race, sex ratios, and whether the couple was cohabiting at baseline. We see even more dramatic improvement in the cohabiting sample in Figure 1.

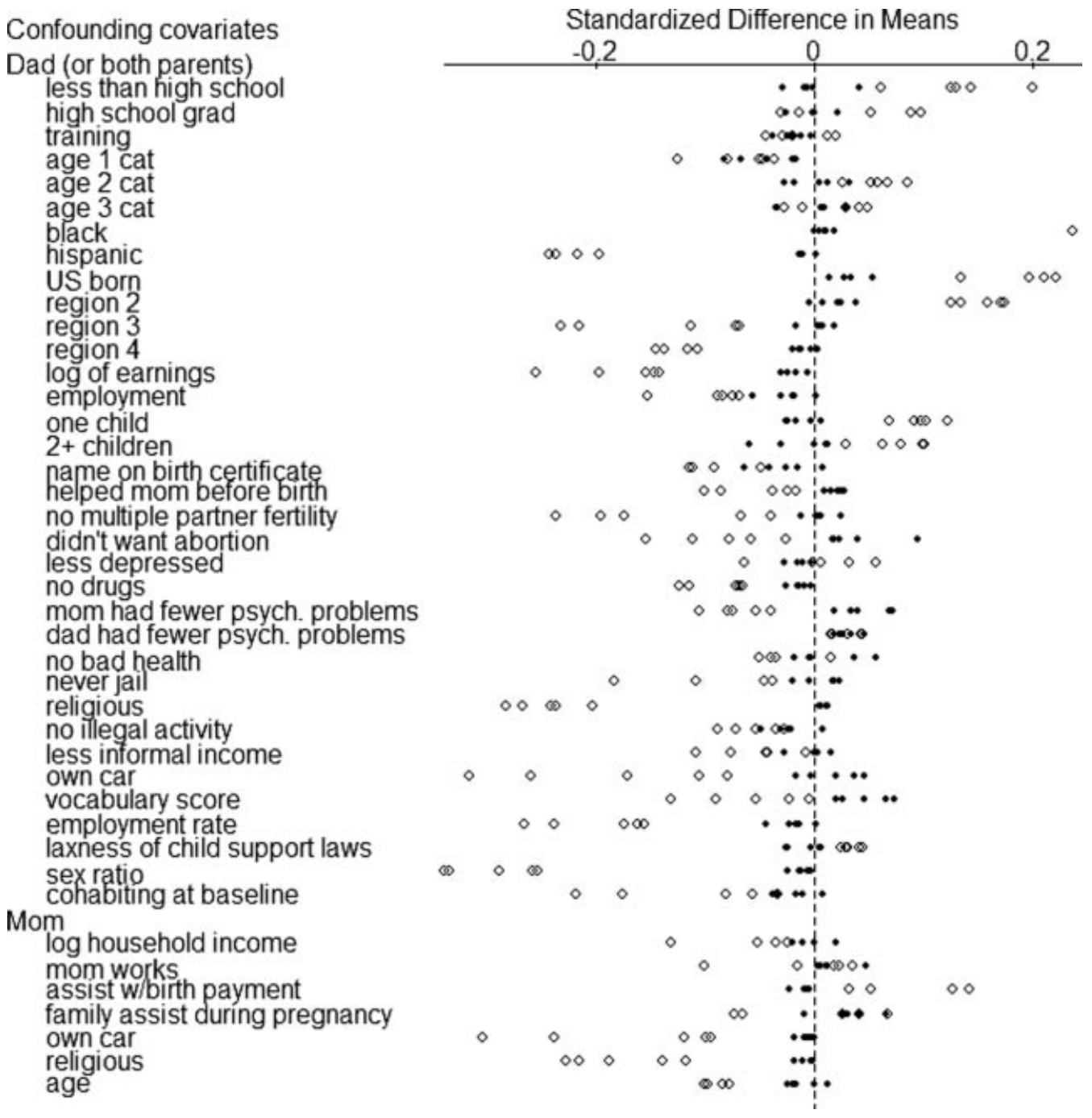

Figure B2. Standardized difference in means for each covariate from Model 5 for both weighted (solid dots) and unweighted (open circles) approaches, displayed as a separate value for each imputed data set. This figure corresponds to the cohabiting sample. 


\section{APPENDIX C: MULTIPLE IMPUTATION APPENDIX}

The basic concepts underlying our multiple imputation strategy are as follows:

1. Impute the missing values using an appropriate model that incorporates random variation. The 88 variables in our model were derived from three sources: (1) fathers' self-reports, (2) mothers' self-reports, and (3) mothers' reports of fathers.

2. Do this $M$ times, producing $M$ “complete" data sets. In our study, $M=5$; that is, five complete case data sets were imputed.

3. Perform the desired analysis on each data set using standard complete-data methods.

4. Average the values of the parameter estimates across the $M$ samples to produce a single point estimate.

5. Calculate the standard errors by (a) averaging the squared standard errors of the $M$ estimates, (b) calculating the variance of the $M$ parameter estimates across samples, and (c) combining the two quantities using a simple formula. Standard errors that account for inter- and intra-data set variation were computed according to the rules laid out by Rubin (1987).

The multiple imputation computations were implemented in Stata (Royston, 2004) using the multivariate imputation by chained equations (MICE) method of multiple multivariate imputation described by van Burren, Boshuizen, and Knock (1999). The application in Stata was developed by Patrick Royston (2004).

Table C1 shows the overall response rates for fathers at each of the first three waves of data. The baseline response rate for all fathers is 78 percent and, while the rate remains stable between the one-year and three-year interviews, it is about 10 percentage points lower than at baseline. This pattern is similar for both married and unmarried fathers-about 89 percent for married fathers and 75 percent for unmarried fathers.

Regarding the 88 variables in the MI model, roughly one-fourth to one-third of the data are imputed across all father-reported variables. By contrast, similar proportions of missing data are found for only one-third of the mother-reported variables. For the remaining two-thirds, only 10 percent of the data are missing. The number of missing variables per observation ranges from a high of 80 percent for one observation to complete data for 15 percent of the 4,898 observations. Fully half of the observations have eight or fewer missing variables, while for the 10 percent of fathers at the high end of the missingness scale, one-third to one-half of the variables in the model are imputed. To illustrate, Table C2 shows the percentage of multiply imputed data for each variable in our cross-sectional and differenced models (see Table 1 for descriptive statistics for these models).

Table C1. Scope of missing data.

\begin{tabular}{lccc}
\hline & \multicolumn{3}{c}{ Percentage of Fathers Interviewed } \\
\cline { 2 - 4 } & Wave 1 & Wave 2 & Wave 3 \\
\hline Full sample & 78 & 69 & 67 \\
Married & 89 & 81 & 81 \\
Unmarried & 75 & 65 & 63 \\
\hline
\end{tabular}


To examine the sensitivity of the results to the method of imputation, we estimated our first two sets of models, the cross-sectional and difference equations, using both complete case and multiply imputed samples. For the most part, the differences between these two strategies were not substantial and in no case did they alter statistical significance. These results are available upon request from the authors

Table C2. Percent of data multiply imputed for cross-sectional and differenced variables.

\begin{tabular}{|c|c|c|c|}
\hline & Married & & cried \\
\hline & $(N=582)$ & All $(N=2,260)$ & Cohabit $(N=847)$ \\
\hline $\begin{array}{l}\text { Cross-Sectional Strateg } \\
\text { Outcome Variable }\end{array}$ & & & \\
\hline 3-Year earnings & 36 & 36 & 25 \\
\hline Covariates & & & \\
\hline Age & 15 & 17 & 11 \\
\hline Race & 15 & 17 & 12 \\
\hline U.S. born & 15 & 17 & 11 \\
\hline Region & 0 & 0 & 0 \\
\hline Education & 34 & 30 & 19 \\
\hline Training & 44 & 43 & 35 \\
\hline Differenced Strategy & & & \\
\hline Outcome Variables & & & \\
\hline Change in Earnings & & & \\
\hline 3 -year earnings & 36 & 36 & 25 \\
\hline Baseline earnings & 22 & 25 & 18 \\
\hline Covariates & & & \\
\hline Additional Education & 39 & 46 & 48 \\
\hline Additional Training & 38 & 37 & 27 \\
\hline
\end{tabular}


APPENDIX D: TABLES CORRESPONDING TO THE INFORMATION DISPLAYED IN FIGURES 2, 3, AND 4

Table D1. Cross-section and differenced estimates of the marriage differential at 3 years post-birth: Standard earnings equations (corresponds to Figure 1) (standard errors in parentheses).

\begin{tabular}{llccc}
\hline & \multicolumn{2}{c}{$\begin{array}{c}\text { Full Sample } \\
\text { Cross-Section/Differenced }\end{array}$} & \multicolumn{2}{c}{$\begin{array}{c}\text { Cohabiters } \\
\text { Cross-Section/Differenced }\end{array}$} \\
\hline Race/Ethnicity & & & & \\
White & $0.28(0.35)$ & $0.13(0.35)$ & $0.05(0.36)$ & $-0.03(0.36)$ \\
Black & $0.77(0.30)$ & $0.27(0.26)$ & $0.60(0.30)$ & $0.11(0.24)$ \\
Hispanic & $0.07(0.29)$ & $0.17(0.30)$ & $-0.10(0.32)$ & $0.04(0.27)$ \\
Observations & 2,842 & 2,842 & 1,163 & 1,163 \\
$R$-Squared & 0.07 & 0.00 & 0.07 & 0.00 \\
\hline
\end{tabular}

Table D2. Effects of marriage on year-5 (log) earnings by race (WBH) for regression and propensity score strategies (corresponds to Figure 2) (standard errors in parentheses)

\begin{tabular}{|c|c|c|c|c|c|c|}
\hline \multirow[b]{2}{*}{ Model } & \multicolumn{2}{|c|}{ Set (A) } & \multicolumn{2}{|c|}{ Set $(A)+(B)$} & \multicolumn{2}{|c|}{ Set $(A)+(B)+(C)$} \\
\hline & $p$-Score & Regression & $p$-Score & Regression & $p$-Score & Regression \\
\hline \multicolumn{7}{|l|}{ Full Sample } \\
\hline White & $\begin{array}{c}0.42 \\
(0.39)\end{array}$ & $\begin{array}{c}0.14 \\
(0.51)\end{array}$ & $\begin{array}{c}0.19 \\
(0.44)\end{array}$ & $\begin{array}{c}0.24 \\
(0.39)\end{array}$ & $\begin{array}{c}0.11 \\
(0.50)\end{array}$ & $\begin{array}{c}0.22 \\
(0.38)\end{array}$ \\
\hline Black & $\begin{array}{c}0.46 \\
(0.36)\end{array}$ & $\begin{array}{c}0.16 \\
(0.37)\end{array}$ & $\begin{array}{c}0.37 \\
(0.49)\end{array}$ & $\begin{array}{c}0.34 \\
(0.28)\end{array}$ & $\begin{array}{c}0.42 \\
(0.48)\end{array}$ & $\begin{array}{c}0.34 \\
(0.28)\end{array}$ \\
\hline Hispanic & $\begin{array}{c}0.08 \\
(0.33)\end{array}$ & $\begin{array}{c}-0.10 \\
(0.32)\end{array}$ & $\begin{array}{c}-0.02 \\
(0.31)\end{array}$ & $\begin{array}{c}-0.14 \\
(0.30)\end{array}$ & $\begin{array}{c}-0.07 \\
(0.30)\end{array}$ & $\begin{array}{c}-0.15 \\
(0.30)\end{array}$ \\
\hline Observations & 2,669 & 2,669 & 2,602 & 2,669 & 2,602 & 2,669 \\
\hline$R$-Squared & 0.07 & 0.02 & 0.16 & 0.16 & 0.17 & 0.16 \\
\hline \multicolumn{7}{|l|}{ Cohabiters } \\
\hline White & $\begin{array}{c}0.33 \\
(0.50)\end{array}$ & $\begin{array}{c}0.38 \\
(0.48)\end{array}$ & $\begin{array}{c}0.17 \\
(0.49)\end{array}$ & $\begin{array}{c}0.30 \\
(0.46)\end{array}$ & $\begin{array}{c}0.17 \\
(0.53)\end{array}$ & $\begin{array}{c}0.31 \\
(0.45)\end{array}$ \\
\hline Black & $\begin{array}{c}0.29 \\
(0.39)\end{array}$ & $\begin{array}{c}0.30 \\
(0.34)\end{array}$ & $\begin{array}{c}0.24 \\
(0.45)\end{array}$ & $\begin{array}{c}0.17 \\
(0.31)\end{array}$ & $\begin{array}{c}0.16 \\
(0.42)\end{array}$ & $\begin{array}{c}0.16 \\
(0.30)\end{array}$ \\
\hline Hispanic & $\begin{array}{c}0.04 \\
(0.30)\end{array}$ & $\begin{array}{c}-0.05 \\
(0.30)\end{array}$ & $\begin{array}{c}-0.09 \\
(0.29)\end{array}$ & $\begin{array}{c}-0.12 \\
(0.28)\end{array}$ & $\begin{array}{c}-0.11 \\
(0.30)\end{array}$ & $\begin{array}{c}-0.12 \\
(0.28)\end{array}$ \\
\hline Observations & 1,581 & 1,581 & 1,558 & 1,581 & 1,558 & 1,581 \\
\hline$R$-Squared & 0.05 & 0.05 & 0.15 & 0.16 & 0.16 & 0.17 \\
\hline
\end{tabular}


Table D3. Impact of adjustment for additional baseline confounding covariates on crosssection (dot) and difference (triangle) estimates of the effect of marriage on year-3 (log) earnings (corresponds to Figure 3) (standard errors in parentheses).

\begin{tabular}{|c|c|c|c|c|c|c|}
\hline \multirow[b]{2}{*}{ Model } & \multicolumn{2}{|c|}{ Set $(A)$} & \multicolumn{2}{|c|}{ Set $(A)+(B)$} & \multicolumn{2}{|c|}{ Set $(A)+(B)+(C)$} \\
\hline & $\begin{array}{l}\text { Cross- } \\
\text { Section }\end{array}$ & Differenced & $\begin{array}{l}\text { Cross- } \\
\text { Section }\end{array}$ & Differenced & $\begin{array}{l}\text { Cross- } \\
\text { Section }\end{array}$ & Differenced \\
\hline \multicolumn{7}{|l|}{ Full Sample } \\
\hline White & $\begin{array}{c}0.28 \\
(0.35)\end{array}$ & $\begin{array}{c}0.13 \\
(0.35)\end{array}$ & $\begin{array}{c}0.09 \\
(0.36)\end{array}$ & $\begin{array}{c}0.08 \\
(0.34)\end{array}$ & $\begin{array}{c}0.08 \\
(0.36)\end{array}$ & $\begin{array}{c}0.07 \\
(0.34)\end{array}$ \\
\hline Black & $\begin{array}{c}0.77 \\
(0.30)\end{array}$ & $\begin{array}{c}0.27 \\
(0.26)\end{array}$ & $\begin{array}{c}0.57 \\
(0.30)\end{array}$ & $\begin{array}{l}0.56 \\
(0.29)\end{array}$ & $\begin{array}{c}0.55 \\
(0.30)\end{array}$ & $\begin{array}{c}0.54 \\
(0.29)\end{array}$ \\
\hline Hispanic & $\begin{array}{c}0.07 \\
(0.29)\end{array}$ & $\begin{array}{c}0.17 \\
(0.30)\end{array}$ & $\begin{array}{c}-0.08 \\
(0.32)\end{array}$ & $\begin{array}{c}-0.08 \\
(0.25)\end{array}$ & $\begin{array}{c}-0.08 \\
(0.32)\end{array}$ & $\begin{array}{c}-0.08 \\
(0.25)\end{array}$ \\
\hline Observations & 2,842 & 2,842 & 2,842 & 2,842 & 2,842 & 2,842 \\
\hline$R$-Squared & 0.07 & 0.00 & 0.15 & 0.38 & 0.15 & 0.38 \\
\hline \multicolumn{7}{|l|}{ Cohabiters } \\
\hline White & 0.05 & -0.03 & -0.13 & -0.12 & -0.13 & -0.13 \\
\hline Black & $(0.36)$ & $(0.36)$ & $(0.35)$ & $(0.35)$ & $(0.35)$ & $(0.34)$ \\
\hline & 0.60 & 0.11 & 0.44 & 0.42 & 0.42 & 0.40 \\
\hline Hispanic & $(0.30)$ & $(0.24)$ & $(0.29)$ & $(0.29)$ & $(0.28)$ & $(0.28)$ \\
\hline & -0.10 & 0.04 & -0.12 & -0.11 & -0.12 & -0.11 \\
\hline Observations & 1,163 & 1,163 & 1,163 & 1,163 & 1,163 & 1,163 \\
\hline$R$-Squared & 0.07 & 0.00 & 0.17 & 0.43 & 0.18 & 0.43 \\
\hline
\end{tabular}


APPENDIX E: TEMPORAL ORDERING OF VARIABLES USED IN EACH ANALYSIS STRATEGY
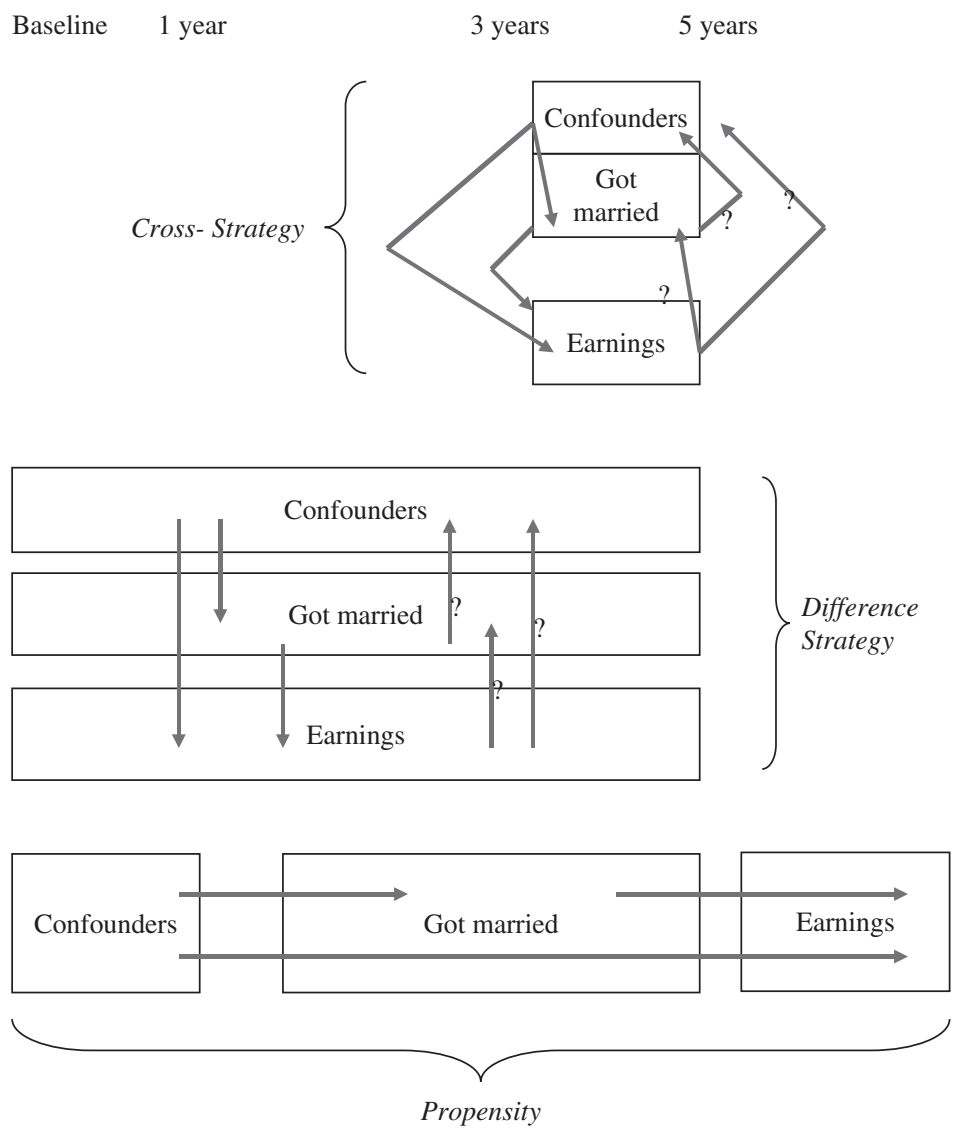

Figure E1. Temporal Ordering of Variables Used in Each Analysis Strategy. 